\title{
A general one-dimensional vertical ecosystem model of Lake Shira (Russia, Khakasia): description, parametrization and analysis
}

\author{
I. G. Prokopkin · W. M. Mooij · J. H. Janse • \\ A. G. Degermendzhy
}

Received: 20 May 2009/Accepted: 18 May 2010/Published online: 10 June 2010

(C) Springer Science+Business Media B.V. 2010

\begin{abstract}
A one-dimensional ecological model of the meromictic brackish Lake Shira (Russia, Khakasia) was developed. The model incorporates state-of-the-art knowledge about the functioning of the lake ecosystem using the most recent field observations and ideas from PCLake, a general ecosystem model of shallow freshwater lakes. The model of Lake Shira presented here takes into account the vertical dynamics of biomasses of the main species of algae, zooplankton and microbial community, as well as the dynamics of oxygen, detritus, nutrients and hydrogen sulphide from spring to autumn. Solar radiation, temperature and diffusion are modelled using real meteorological data. The parameters of the model were calibrated to the field data, after applying different methods of sensitivity analysis to the model. The resulting patterns of phytoplankton and nutrients dynamics show a good qualitative and quantitative
\end{abstract}

Handling Editor: R. D. Gulati.

I. G. Prokopkin $(\varangle)$ · A. G. Degermendzhy

Institute of Biophysics, Akademgorodok,

660036 Krasnoyarsk, Russia

e-mail: Prokop@ibp.ru

W. M. Mooij

Netherlands Institute of Ecology, Centre for Limnology,

Rijksstraatweg 6, 3631 AC Nieuwersluis,

The Netherlands

J. H. Janse

Netherlands Environmental Assessment Agency (PBL), Postbus 303, 3720 AH Bilthoven, The Netherlands agreement with the field observations during the whole summer season. Results are less satisfactory with respect to the vertical distribution of zooplankton biomass. We hypothesize that this is due to the fact that the current model does not take the sex and age structure of zooplankton into account. The dynamics of oxygen, hydrogen sulphide and the modelled positions of the chemocline and thermocline are again in good agreement with field data. This resemblance confirms the validity of the approach we took in the model regarding the main physical, chemical and ecological processes. This general model opens the way for checking various hypotheses on the functioning of the Lake Shira ecosystem in future investigations and for analysing options for management of this economically important lake.

Keywords Meromictic brackish lake . One-dimensional vertical ecological model . Sensitivity analysis

\section{Introduction}

Meromictic lakes form a relatively small category of natural reservoirs. Important features of such lakes are the strong vertical gradients in temperature, density and chemical and in many cases a low species diversity. These characteristics have consequences for ecosystem functioning and the biochemical cycling of elements in these lakes. A key distinction the sets 
meromictic lakes apart from other reservoirs is the presence of a non-mixing bottom-water layer-the monimolimnion. Typically, the monimolimnion is anaerobic, and therefore unsuitable as a habitat for most live forms except bacteria.

Lake Shira (Russia, Khakasia) is a typical example of a meromictic natural reservoir. The use of this reservoir as the popular recreation place and its balneological properties put special constraints on its water quality. During recent years, several studies on the structure and functioning of Lake Shira were performed (Zotina et al. 1999; Gaevsky et al. 2002; Kalacheva et al. 2002; Kopylov et al. 2002b) and a first mathematical model of the lake's ecosystem was created (Degermendzhy et al. 2002).

The main focus of this first model was on the simulation of the sulphur cycle in the chemocline and to study different mechanisms and hypotheses about the formation of the vertical distribution of biochemical components in the lake. When confronted with the data about the structure of lake ecosystem; however, it became clear that further model development was necessary. In particular, the earlier model failed to correctly describe algae and cyanobacteria in the lake and did not look at the nitrogen cycle at all. Based on the earlier model and taking advantage of the experience of modelling aquatic ecosystems with the general ecosystem model for shallow holomictic lakes PCLake (Janse 2005), a new mathematical model of Lake Shira was developed and presented in this paper.

The first aim of this study is to accumulate in the new model the latest insights into the structure and functioning of Lake Shira resulting from recent investigations (Pimenov et al. 2003; Tolomeyev et al. 2006; Lunina et al. 2007; Zadereev and Tolomeyev 2007; Rogozin et al. 2009). The second aim is to introduce to a more advanced hydrodynamical algorithm (Belolipetsky et al. 2010) and new algorithms for modelling phytoplankton, zooplankton, nutrients and detritus, on basis of PCLake (Janse 2005). The third aim is to investigate the mechanisms and factors causing the vertical profiles of the main biochemical components in the lake.

\section{The choice of dimension in lake models}

Nowadays, the application of coupled hydrophysical and biochemical models in the ecological study of the lakes is a common approach and a variety of $1 \mathrm{D}$ vertical, $2 \mathrm{D}$ and $3 \mathrm{D}$ models have developed for different lakes (Bonnet and Wessen 2001; Omlin et al. 2001; Trolle et al. 2008) and ecological questions (Bruce et al. 2006; Burger et al. 2008).

The complexity of the description of the hydrophysical processes varies considerably among these models. There are quite a few relatively simple advective-diffusive models (Reichert 1994) but also more complex models based on turbulence scheme (Antonopoulos and Gianniou 2003; Gal et al. 2003). There are no strict guidelines for the selection of the spatial dimension in the lake models and different models use different dimensions (Romero et al. 2004). But it is clear that a more accurate description of the hydrodynamic parts of the model will increase the accuracy of the biochemical properties of the model.

Obviously there is the wide set of the cases when the assumption of $1 \mathrm{D}$ vertical model may be restrictive. Large and complex shape of the basins and the presence of intensive inflows/outflows can give rise to the intensive hydrodynamical processes in the lakes in the horizontal plane. In these cases, higher dimensional models (2D and 3D) are more useful tools and will give a more complete description of such lakes. However, the opposite cases exist too, when the application of multidimensional models is unjustified. As a rule of thumb, it seems that in most cases 1D vertical is enough for modelling of small and medium size lakes or in cases when vertical variations in variables are more essential than horizontal. Also we should understand that the addition of the each spatial dimension requires more data for model validation. Sometimes a lack of field data may be an essential obstacle for the usage of multidimensional (2D and 3D) models.

In the current study, we present a new and general $1 \mathrm{D}$ vertical model of the water column in the central part of Lake Shira (Russia, Khakasia). Field observations convincingly show that during the summer there is a strong spatial heterogeneity in the vertical coordinate of the water column of this lake (Gaevsky et al. 2002; Kopylov et al. 2002a) and the concentrations of most ions increased with depth (Kalacheva et al. 2002). At the same time, the chemical composition of water in the horizontal extend was found to be fairy homogeneous (Kalacheva et al. 2002). In this case, the development of $1 D$ vertical model seems valid. The one-dimensional model 
allows calculating the vertical distributions of the various chemical and biological components of the system. For a meromictic lake, this capacity is essential for understanding the processes in the ecosystem and their dynamics.

\section{Description of Shira Lake}

Lake Shira is a meromictic brackish reservoir. The maximum depth of lake equals $23-25 \mathrm{~m}$. The surface area of the reservoir is $35.9 \mathrm{~km}^{2}$. The lake has an elliptical form with characteristic dimensions $9.35 \times 5.3 \mathrm{~km}$. The reservoir is located in the Republic of Khakasia (Russia) with the following geographical coordinates: $54^{\circ} 29^{\prime}$ north latitude and $90^{\circ} 14^{\prime}$ east longitude.

Lake Shira displays a permanent stratification of physical-chemical and biological components, with the development of a sulphur bacterial community in the chemocline (Kopylov et al. 2002a). The hydrogen sulphide zone during the summer season begins at a depth of $11-12 \mathrm{~m}$. The thermocline is observed during whole summer at the depth 5-8 $\mathrm{m}$. The pelagic zone of Lake Shira is characterized by a relatively small variety of zooplankton species. Cyanobacteria Lyngbya and green algae Dictyosphaerium dominate in phytoplankton. There is no predatory zooplankton in lake. The fish has appeared in the lake only last years in small numbers and only near the point where rivers enter the lake.

A detailed description of the reservoir and its ecosystem can be found in the work of Zotina et al. (1999), Gaevsky et al. (2002), Kalacheva et al. (2002), Kopylov et al. (2002b), Rogozin et al. (2009).

\section{Description of the model}

\section{Short review of the earlier model}

The earlier model described a one-dimensional vertical spatial component of the water column in the central part of the Lake Shira. The list of biochemical variables contained two dominant species of phytoplankton, one species of dominant crustacean, microorganisms involved in a cycle of sulphur, mineral phosphorus, organic matter, oxygen, hydrogen sulphide and sulphur.
Phytoplankton was represented in the model by green algae Dictyosphaerium tetrachotomum (Chlorophyta) and cyanobacteria Lyngbya contorta (Cyanophyta). Zooplankton was represented by dominant crustacean Arctodiaptomus salinus. Microorganisms involved in a cycle of sulphur were represented by sulphate-reducing bacteria (genera Desulfovibrio, Desulfotomaculum, Desulfobacter etc.), purple sulphur bacteria (Chromatiaceae), green sulphur bacteria (Chlorobiaceae) and non-coloured sulphur bacteria (Thiobacillus).

The vertical distribution of biochemical variables were calculated using differential equations with the following structure:

$\frac{\partial C}{\partial t}+W g \frac{\partial C}{\partial z}=\frac{\partial}{\partial z}\left(K_{z} \frac{\partial C}{\partial z}\right)+F$

where $C$ is the state variable, $W g \frac{\partial C}{\partial z}$ represents the process of sinking or emerge, $W g$ is the rate of sinking or emerge, $\frac{\partial}{\partial z}\left(K z \frac{\partial C}{\partial z}\right)$ represents the process of diffusion, $K_{z}$ is turbulent diffusion coefficient, $F$ represents function describing the biochemical interaction of variable $C$ with other components.

The calculations employed the constant turbulent diffusion coefficient $K_{z}$, which is the same for all variables. Sedimentation was defined only for organic matter. The intensity of solar radiation on the surface of the lake had a constant value during the calculations. Three spectra of radiation were separated for different groups of organisms. The attenuation of light in the water column was described with the law of Lambert-Beer. Detailed description of this earlier model can be found in Degermendzhy et al. (2002).

The hydrodynamical algorithm in the model

We used a one-dimensional model of the hydrodynamic and thermal structure of Lake Shira (Belolipetsky et al. 2010). Formulation of the temperature regime is carried out by wind-induced mixing, solar heating and heat exchange with atmosphere. The turbulence exerts primary control over heat-mass transfer. For parameterization of vertical turbulence mixing, we based ourselves on the Prandtl-Obuchov formula and the approximated solution for windforced flow (Belolipetskii and Genova 1998). The meteorological data input to the model includes cloud cover, air temperature, vapour pressure, wind speed 
and direction. The model allows the identification of the position of the thermocline and the halocline, the intensity of vertical mixing and the vertical distributions of temperature, salinity and density, all depending on meteorological conditions.

The structure of the model

\section{Model variables}

In accordance with recent field observations (Pimenov et al. 2003), the variables and the processes for noncoloured sulphur bacteria and green sulphur bacteria were not taken into account in the new model. The component organic matter, which only accumulated the fluxes of dead matter in the earlier model, was replaced by the component detritus, which also accumulates the fluxes from mortality and egestion processes. Also sulphur was not taken into account because this variable is not important for the description of the lake ecosystem under study.

We have added in the model new variables and processes for ammonium and nitrate as these are important nutrients in any ecosystem. In accordance with the paper of Tolomeyev et al. (2006), the amphipods Gammarus lacustris was introduced in the new model also.

Phytoplankton, zooplankton and detritus in new model each are described in three state variables with different dimensions: $\mathrm{mgDW} \mathrm{l}^{-1}, \mathrm{mgP}^{-1}, \mathrm{mgN}^{-1}$. Such an approach is needed to describe the dynamic stoichiometry of these model components, which is an important aspect of the general ecosystem model for shallow lakes PCLake (Janse 2005). This variable stoichiometry is expressed in the ratios of $\mathrm{P}$ or $\mathrm{N}$ to biomass (the latter expressed in units of dry weight sets and a proxy for the carbon content of a biological model component):

$$
\begin{aligned}
& r P D \text { Spec }=\operatorname{sPSpec} W[i] / \text { sDSpec } W[i], \\
& r N D \text { Spec }=\operatorname{sNSpec} W[i] / \operatorname{sDpec} W[i],
\end{aligned}
$$

where $r P D$ Spec is the current content of phosphorus in the modelled component $\left(\mathrm{mgP} \mathrm{mgDW}^{-1}\right), r N D$ Spec is the current content of nitrogen in the modelled component $\left(\mathrm{mgN} \mathrm{mgDW}^{-1}\right)$, suffix Spec $=$ Gren for green algae, = Blue for cyanobacteria, = Zoo for zooplankton, = Det for detritus.

The dimension of variables that describes the bacterial community and the amphipods is $\operatorname{mgDW~} 1^{-1}$. The remaining variables have a dimension $\mathrm{mg}^{-1}$.

A list of all biochemical variables of the vertical model of Lake Shira (identifier, definition and units of variables) is shown in Table 1.

\section{Forcing functions}

The intensity of solar radiation, weakened by the atmosphere and falling on the surface of the reservoir, has a seasonal and diurnal rhythm.

PAR is separated from solar energy. Two spectra of radiation sLight $1[i]$, sLight $2[i]$ are separated in

Table 1 Biochemical state variables of the vertical model of Lake Shira

\begin{tabular}{lll}
\hline Variables & Definition & Unit \\
\hline sDGrenW, sPGrenW, sNGrenW & Green algae & $\mathrm{mgDW}^{-1}, \mathrm{mgP}^{-1}, \mathrm{mgN}^{-1}$ \\
sDBlueW, sPBlueW, sNBlueW & Bluegreen algae & $\mathrm{mgDW}^{-1}, \mathrm{mgP}^{-1}, \mathrm{mgN}^{-1}$ \\
sDZooW, sPZooW, sNZooW & Zooplankton & $\mathrm{mgDW}^{-1}, \mathrm{mgP}^{-1}, \mathrm{mgN}^{-1}$ \\
sDGammW & Amphipods & $\mathrm{mgDW}^{-1}$ \\
sDSPBactW & Purple sulphur bacteria & $\mathrm{mgDW}^{-1}$ \\
sDSRBactW & Sulphate-reducing bacteria & $\mathrm{mgDW}^{-1}$ \\
sO2 W & Dissolved oxygen & $\mathrm{mg}^{-1}$ \\
sH2SW & Dissolved hydrogen sulphide & $\mathrm{mg}^{-1}$ \\
sPO4W & Dissolved phosphorus, PO4 & $\mathrm{mg}^{-1}$ \\
sNH4W & Dissolved ammonium, NH4 & $\mathrm{mg}^{-1}$ \\
sNO3W & Dissolved nitrate, NO3 & $\mathrm{mg}^{-1}$ \\
sDDetW, sPDetW, sNDetW & Detritus & $\mathrm{mgDW}^{-1}, \mathrm{mgP}^{-1}, \mathrm{mgN}^{-1}$ \\
\hline
\end{tabular}


PAR: first spectra for phytoplankton, second-for purple sulphur bacteria. The reason for the separation of PAR is in the different light requirements of different groups of microorganisms that should be taken into account for realistic modelling of the vertical distributions of phytoplankton and bacteria: 550-700 nm for green algae and cyanobacteria; 450$550 \mathrm{~nm}$ and $800-900 \mathrm{~nm}$ for purple sulphur bacteria (Degermendzhy et al. 2002). If we would ignore this, the bacteria will have no light for growth due to the shade from phytoplankton that lives higher up in the column. In reality, these groups of microorganisms use different parts of the light spectrum and we should take this fact into account in our model.

Light attenuation in the water column is described with the law of Lambert-Beer, together with the light absorbing properties of water, detritus and biological components at any point in time (Table 2).

The model takes into account the cloud cover, air temperature, vapour pressure, wind speed and direction during the day as meteorological data for hydrodynamical algorithm. An array of these data is established for each day during a few years.

\section{The processes of diffusion and sedimentation}

The part $\frac{\partial}{\partial z}\left(K z \frac{\partial C}{\partial z}\right)$ of Eq. 1 represents the process of diffusion in our model. In the earlier model, the turbulent diffusion coefficient $K_{z}$ was assumed constant in time and the same for all variables during the calculations (Degermendzhy et al. 2002). In the new model, $K_{z}$ is a dynamic function, and different groups of variables have different values of $K_{z}$.

For modelling the vertical distribution of dissolved substances in water, such as, oxygen, nitrogen and phosphorus, detritus and others, value of turbulent diffusion coefficients $K_{z}$ can be assumed to be the same as in the equations of heat transfer in water (Rukhovets et al. 2003).

In case of modelling, the vertical distribution of phytoplankton, the values of the turbulent diffusion coefficients should be less than those used in the calculation of dissolved substances in water (Rukhovets et al. 2003). Similar considerations are true for describing the spatial distribution of various types of bacteria.

Using diffusion to describe the vertical distribution of zooplankton and amphipods is less justified, because zooplankton and amphipods, which perform intensive individual vertical migrations, cannot be considered as hydrodynamically neutral. Nevertheless, the use of such equations is possible but requires calibration of the relevant diffusion parameters from field data.

The introduction into the model these new features resulted in additional coefficients of proportionality $c K_{z}$ SpecCorr, where suffix Spec $=$ Gren for green algae, = Blue for cyanobacteria, = Zoo for zooplankton, = Gamm for amphipods, = SRBact for sulphate-reducing bacteria, = SPBact for purple sulphur bacteria. The values of turbulent diffusion coefficient for these variables are defined as the multiplication $c K_{z}$ SpecCorr $K_{z}$, where $K_{z}$ is turbulent diffusion coefficient for dissolved substances (oxygen and nitrogen etc.). After the calibration, the values of $c K_{z}$ SpecCorr were determined for green algae to be equal to $0.3,0.2$ for cyanobacteria, 0.1 for sulphatereducing and purple sulphur bacteria, 0.05 for amphipods and 0.95 for zooplankton.

The process of sinking, which is set as $\frac{\partial W g C}{\partial z}$ in Eq. 1, is defined in the new model only for the small size particles such as phytoplankton and detritus.

The presence of temperature and density stratifications in the summer is typical for meromictic

Table 2 Summary of basic equations for light in the water column

\begin{tabular}{|c|c|}
\hline Light intensity & Equations \\
\hline The first spectrum in zero depth & $\begin{array}{l}\text { sLight } 1[0]=L O u t \cdot f P A R \cdot(1-f \operatorname{Re} f r) \cdot f P a r t 1, \text { where LOut-light intensity above the water } \\
\text { surface }\end{array}$ \\
\hline The first spectrum in the $i$ depth & $\begin{array}{l}\text { sLight } 1[i]=\operatorname{sLight} 1[i-1] \cdot \exp (- \text { gamma } 1 \cdot d h \cdot \ln (10)), \text { where } \\
\quad \text { gamma } 1=c E x t \text { Wat }+c \text { ExtDet } \cdot \operatorname{sDDet} W[i]+c \text { ExtBlue } \cdot \text { sDBlueW }[i]+\text { cExtGren } \cdot \text { sDGrenW }[i]\end{array}$ \\
\hline $\begin{array}{l}\text { The second spectrum in zero } \\
\text { depth }\end{array}$ & $s L i g h t 2[0]=L O u t \cdot f P A R \cdot(1-f \operatorname{Re} f r) \cdot f$ Part 2 \\
\hline $\begin{array}{l}\text { The second spectrum in the } i \\
\text { depth }\end{array}$ & $\begin{array}{l}\text { sLight } 2[i]=\operatorname{sLight} 2[i-1] \cdot \exp (- \text { gamma } 2 \cdot d h \cdot \ln (10)), \text { where } \\
\quad \text { gamma } 2=c E x \text { Wat }+ \text { cExtDet } \cdot \text { sDDetW }[i]+c \text { ExtSPBact } \cdot \text { sDSPBact } W[i]\end{array}$ \\
\hline
\end{tabular}


reservoirs. With the increase in salinity and/or decrease in temperature, the viscosity of the water increases and the velocity of sinking decreases as a result. We had to consider this phenomenon in modelling the process of sinking. In summer, the temperature stratification of the oxic zone of Lake Shira is very pronounced while there is little change in salinity. Therefore, temperature has the greatest influence on the velocity of sinking of modelled components. The velocity of sinking is maximal in the epilimnion and significantly reduces below the thermocline.

In particular, the dependence of the sinking velocity on temperature is set as follows (Janse 2005):

$W g(T)=w g_{\max }$ Spec $\cdot \theta_{\text {sed }}^{T-T^{0}}$,

where $T$ is water temperature $\left({ }^{\circ} \mathrm{C}\right), w g_{\max }$ Spec is the maximum sedimentation rate of Spec $\left(\mathrm{m} \mathrm{day}^{-1}\right), T^{0}$ is reference temperature $\left({ }^{\circ} \mathrm{C}\right), \theta_{\text {sed }}$ is temperature constant of sedimentation $\left(1 / e^{\circ} \mathrm{C}\right)$, Spec $=$ Gren for green algae, = Blue for cyanobacteria, = Det for detritus.

\section{Boundary conditions}

To solve the Eq. 1, the boundary conditions are set at zero and maximum depth. In the new model, nonzero boundary conditions are defined only for four variables: oxygen, hydrogen sulphide, phosphorus and ammonia.

The process of diffusion of oxygen from the atmosphere in the water column is defined as the boundary condition at zero depth. The equations describing the dependence of the speed of diffusion of oxygen on the water temperature and wind force on the surface of the reservoir are taken form the work by Janse (2005). For mineral phosphorus and ammonia, a constant loading of the reservoir is defined as the boundary conditions at zero depth too. Finally, a boundary condition is set for hydrogen sulphide, describing the measured (unpublished data) continuous flux of this substance from the sediment to the reservoir.

\section{Description of the biochemical interactions between components}

Biochemical interactions between the variables and other processes are entered in the model using function $F$ (1). A brief description of these functions $F$ and their mathematical terms are given in Appendix 1. Main equations for variables are presented in Tables 3, 4, 5, 6, 7, 8, 9, 10, 11, 12, and 13 . Additional equations of the model are gathered in Appendix 2. Here, we describe the interactions and the processes in words.

The growth of algae and cyanobacteria is determined by the multiplicative effect of light, temperature and nutrients. For the dependence of growth rate on temperature, it is assumed that there is an optimal temperature, outside of which growth of phytoplankton is reduced. According to laboratory experiments and field observations (Zotina 2000; Kopylov et al. 2002a), cyanobacteria show maximum photosynthetic activity for values of radiation equal $1 \%$ of the surface radiation. Green algae Dictyosphaerium tetrachotomum has the same lighting requirements as cyanobacteria Lyngbya contorta. The growth rate of green algae and cyanobacteria also depends on the intracellular content of phosphorus and nitrogen and is determined in accordance with the Liebig's rule of the minimum.

Uptake of nutrients by algae and cyanobacteria depends on the concentration of nutrients in the environment and the current intracellular content.
Table 3 Summary of basic equations for green algae and cyanobacteria (suffix Spec = Gren for green algae, = Blue for cyanobacteria)

\begin{tabular}{|c|c|}
\hline Processes & Equations \\
\hline Growth & $\begin{array}{l}\text { wDAssSpecW }=\text { aMuSpec } \cdot \text { sDSpec } W[i], \text { where } \\
\quad \text { aMuSpec }=\text { cMuMaxSpec } \cdot \text { uFunTmSpec } \cdot \text { aLLimSpec } \cdot \text { aNutLimSpec }\end{array}$ \\
\hline Respiration & $w D \operatorname{RespSpec} W=k D \operatorname{RespSpec} W \cdot u F u n T m S p e c \cdot s D S p e c[i]$ \\
\hline Mortality & $w D M o r t S p e c W=k M o r t S p e c W \cdot s D S p e c W[i]$ \\
\hline $\begin{array}{l}\text { Consumption } \\
\text { by zooplankton }\end{array}$ & $w$ DConsSpecZoo $=c$ Pr efSpec $\cdot w D$ ConsZoo \\
\hline $\begin{array}{l}\text { Consumption } \\
\text { by amphipods }\end{array}$ & wDConsSpecGamm $=c$ Pr efSpec $\cdot$ wDConsGamm \\
\hline
\end{tabular}


Table 4 Summary of basic equations for zooplankton

\begin{tabular}{ll}
\hline Processes & Equations \\
\hline Growth & $w D$ AssZoo $=a M u Z o o \cdot s D Z o o W[i]$, where $a M u Z o o=k M u M a x Z o o \cdot a A \lg \operatorname{LimZoo} \cdot u$ FunTmZoo \\
Respiration & $w D \operatorname{RespZoo}=a$ CorDRespZoo $\cdot k D \operatorname{RespZoo} \cdot u$ FunTmZoo $\cdot s D Z o o W[i]$ \\
Mortality & $w D M o r t Z o o=k M o r t Z o o \cdot s D Z o o W[i]$ \\
\hline
\end{tabular}

Table 5 Summary of basic equations for amphipods

\begin{tabular}{ll}
\hline Processes & Equations \\
\hline Growth & wDAssGamm $=$ aMuGamm $\cdot$ sDGammW $[i]$, where aMuGamm $=c$ MuGamm $\cdot$ uFunTmGamm \\
Mortality & wDMortGamm $=c$ MortGamm $\cdot s D G a m m W[i]$ \\
\hline
\end{tabular}

Table 6 Summary of basic equations for purple sulphur bacteria

\begin{tabular}{|c|c|}
\hline Processes & Equations \\
\hline Growth & $w D A s s S P B a c t W=a M u S P B a c t W \cdot s D S P B a c t W[i]$ \\
\hline Mortality & $w D M o r t S P B a c t W=k M o r t S P B a c t W \cdot s D S P B a c t W[i]$ \\
\hline
\end{tabular}

Table 7 Summary of basic equations for sulphate-reducing bacteria

\begin{tabular}{ll}
\hline Processes & Equations \\
\hline Growth & wDAssSRBactW $=$ aMuSRBactW $\cdot \operatorname{sDSRBactW[i]}$ \\
Mortality & wDMortSRBactW $=k$ MortSRBactW $\cdot \operatorname{sDSRBactW}[i]$ \\
\hline
\end{tabular}

Respiration of algae and cyanobacteria is defined as a process with constant specific rate of the process and temperature correction. The rate of excretion is proportional to the rate of respiration but takes into account the actual contents of nutrients in cells-if contents are decreasing, then rate of excretion is decreasing too. Mortality of phytoplankton is modelled as a constant specific rate. Organic matter, formed by dead algae and cyanobacteria, is divided into two parts-soluble fraction and detritus.

Zooplankton consumes green algae, cyanobacteria and detritus. Growth of zooplankton is limited by the sum of concentrations of these components. Thus, there is a threshold concentration of food, below which the growth of zooplankton stops. In the process of feeding zooplankton consumes various components in proportion to their concentrations in the water layers. Growth of zooplankton also is limited by water temperatures, if its value is not equal to the optimum.

To maintain a balance between the ratios $P / C, N / C$ phosphorus and nitrogen assimilate better than carbon during consumption of food. Part of undigested food is egested by zooplankton and divided into two partssoluble fraction and detritus. Mortality of zooplankton is modelled as a constant specific mortality rate. The flux of dead zooplankton is also divided into a soluble and an insoluble fraction (detritus).

For modelling respiration of zooplankton and excretion of nutrients by zooplankton, the model takes into account the following hypotheses: (a) to maintain the $P / C, N / C$ ratios respiration rate sharply increases at low phosphorus and nitrogen inside organisms; (b) to maintain the $P / C, N / C$ ratio, the rate of excretion of nutrients, is defined to smaller than the respiration rate.

The growth rate of amphipods Gammarus lacustris is limited by temperature only. Amphipods consume seston-detritus and phytoplankton in proportion to their concentrations in the water layers. Mortality of amphipods is modelled as a constant specific mortality rate. The flux of dead amphipods is defined as for zooplankton.

The transformation of sulphur in the model is carried out by two groups of microorganisms: (a) purple sulphur bacteria oxidizing hydrogen sulphide $\mathrm{H}_{2} \mathrm{~S}$ and (b) sulphate-reducing bacteria.

The growth of sulphate-reducing bacteria is inhibited by oxygen and high concentrations of hydrogen sulphide. Mortality of sulphate-reducing bacteria is proportional to their biomass and the constant specific mortality rate. The flux of dead bacteria contributes to the detritus. The process of sulphate-reduction is in the anaerobic zone and limited by detritus only. It is assumed that the high level of sulphate $\left(9-10 \mathrm{~g} \mathrm{l}^{-1}\right.$ in the anaerobic zone, Kalacheva et al. 2002) don't limit the process of sulphate-reduction. 
Table 8 Summary of basic equations for detritus

\begin{tabular}{|c|c|}
\hline Processes & Equations \\
\hline Mortality of phytoplankton & $w D M o r t P h y t W=w D M o r t B l u e W+w D M o r t G r e n W$ \\
\hline Mortality of purple sulphur bacteria & See Table 6 (mortality) \\
\hline Mortality of sulphate-reducing bacteria & See Table 7 (mortality) \\
\hline Mortality of zooplankton & See Table 4 (mortality) \\
\hline Egestion of zooplankton & $w D E g e s Z o o=w D C o n s Z o o-w D A s s Z o o$ \\
\hline Egestion of sulphate-reducing bacteria & $w D E g e s S R B a c t W=w D C o n s D e t S R B a c t W-w D A s s S R B a c t W$ \\
\hline Mineralization & $w D M i n D e t W=k D M i n D e t W \cdot u F u n T m M i n W \cdot s D D e t[i]$ \\
\hline Consumption by sulphate-reducing bacteria & $w D C o n s D e t S R B a c t W=w D A s s S R B a c t W / y O M S R B a c t$ \\
\hline Consumption by zooplankton & $w D C o n s$ DetZoo $=c \operatorname{Pr} e f D e t \cdot w D C o n s Z o o$ \\
\hline Mortality of amphipod & See Table 5 (mortality) \\
\hline Egestion of amphipod & wDEgesGamm = wDConsGamm - wDAssGamm \\
\hline Consumption by amphipod & $w D C o n s$ DetGamm $=c \operatorname{Pr}$ efDet $\cdot w D$ ConsGamm \\
\hline
\end{tabular}

Table 9 Summary of basic equations for phosphorus $\mathrm{PO}_{4}$

\begin{tabular}{|c|c|}
\hline Processes & Equations \\
\hline Excretion of phytoplankton & $w P E x c r P h y t W=w P$ ExcrBlue $W+w P$ ExcrGren $W$ \\
\hline Mortality of phytoplankton & $w P M o r t P h y t P O 4 W=$ fDissMortPhyt $\cdot(w P M o r t B l u e W+w P M o r t G r e n W)$ \\
\hline Mineralization of detritus & $w P M i n D e t W=k D M i n D e t W \cdot u F u n T m M i n W \cdot s P D e t[i]$ \\
\hline Egestion of sulphate-reducing bacteria & wPEgesSRBactWPO4 = wPEgesSRBactW $\cdot$ fDissEgesSRBactWPO4 \\
\hline Excretion of zooplankton & $w P E x c r Z o o=\frac{r P D Z o o}{c P D Z o o \operatorname{Re} f} \cdot k D \operatorname{RespZoo} \cdot s P Z o o W[i]$ \\
\hline Egestion of zooplankton & wPEgesZooPO4 = fDissEgesZoo $\cdot$ wPEgesZoo \\
\hline Mortality of zooplankton & $w P M o r t Z o o P O 4=$ fDissMortZoo $\cdot w P M o r t Z o o$ \\
\hline Uptake by phytoplankton & $w P U p t P h y t=w P U p t B l u e+w P U p t G r e n$ \\
\hline Egestion of amphipod & wPEgesGammPO4 = fDissEgesGamm $\cdot$ wPEgesGamm \\
\hline Mortality of amphipod & wPMortGammPO4 = fDissMortGamm $\cdot$ wPMortGamm \\
\hline
\end{tabular}

Table 10 Summary of basic equations for ammonium $\mathrm{NH}_{4}$

\begin{tabular}{|c|c|}
\hline Processes & Equations \\
\hline Excretion of phytoplankton & $w N E x c r P h y t W=w N E x c r B l u e W+w N E x c r G r e n W$ \\
\hline Mortality of phytoplankton & $w N M o r t P h y t N H 4 W=$ fDissMortPhyt $\cdot(w N M o r t B l u e W+w N M o r t G r e n W)$ \\
\hline Mineralization of detritus & $w N M i n D e t W=k D M i n D e t W \cdot u F u n T m M i n W \cdot s N D e t[i]$ \\
\hline Egestion of sulphate-reducing bacteria & wNEgesSRBactWNH4 $=$ wNEgesSRBactW $\cdot$ fDissEgesSRBactWNH4 \\
\hline Excretion of zooplankton & $w N E x c r Z o o=\frac{r N D Z o o}{c N D Z o o \operatorname{Re} f} \cdot k D \operatorname{RespZoo} \cdot s N Z o o W[i]$ \\
\hline Egestion of zooplankton & $w N E g e s Z o o N H 4=$ fDissEgesZoo $\cdot$ wNEgesZoo \\
\hline Mortality of zooplankton & $w N M o r t Z o o N H 4=$ fDissMortZoo $\cdot w N M o r t Z o o$ \\
\hline Nitrification & $w N N i t r W=k N i t r W \cdot u F u n T m N i t r \cdot a C o r O 2 N i t r W \cdot s N H 4 W[i]$ \\
\hline Uptake by phytoplankton & $w N U p t N H 4 P h y t=w N U p t N H 4 B l u e+w N U p t N H 4 G r e n$ \\
\hline Egestion of amphipod & wNEgesGammNH4 =fDissEgesGamm $\cdot$ wNEgesGamm \\
\hline Mortality of amphipod & $w N M o r t G a m m N H 4=$ fDissMortGamm $\cdot$ wNMortGamm \\
\hline
\end{tabular}


Table 11 Summary of basic equations for nitrate $\mathrm{NO}_{3}$

\begin{tabular}{ll}
\hline Processes & Equations \\
\hline Nitrification & See Table 10 (nitrification) \\
Denitrification & $w N D e n i t W=N O 3 P e r C \cdot \operatorname{molNmolC} \cdot c C P e r D W \cdot \frac{s N O 3 W[i] \cdot(1-a \operatorname{CorO} B O D \text { B })}{s N O 3 W[i]+h N O 3 D e n i t} \cdot w D M i n D e t W$ \\
Uptake by phytoplankton & $w N U p t N O 3 P h y t=w N U p t N O 3 B l u e+w N U p t N O 3 G r e n$ \\
\hline
\end{tabular}

Table 12 Summary of basic equations for hydrogen sulphide $\mathrm{H}_{2} \mathrm{~S}$

\begin{tabular}{ll}
\hline Processes & Equations \\
\hline Sulphate reduction & wH2SFormSRBact $=$ cH2SFormSRBact $\cdot$ wDAssSRBactW \\
Chemical oxidation of hydrogen sulphide & See Table 13 (chemical oxidation of hydrogen sulphide) \\
Oxidation of hydrogen sulphide by purple sulphur bacteria & $w H 2 S O x S P B a c t=w D A s S P B a c t W / y H 2 S S P B a c t$
\end{tabular}

Table 13 Summary of basic equations for oxygen $\mathrm{O}_{2}$

\begin{tabular}{|c|c|}
\hline Processes & Equations \\
\hline Production by phytoplankton & $w O 2 \operatorname{Pr} o d P h y t=\operatorname{molO} 2 \mathrm{molC} \cdot c C P e r D W \cdot(w D A s s G r e n W+w D A s s B l u e W)$ \\
\hline Uptake nitrate by phytoplankton & wO2UptNO3Phyt $=$ O2PerNO3 $\cdot$ molO2molN $\cdot(w N U p t N O 3 B l u e+w N U p t N O 3 G r e n)$ \\
\hline Respiration of phytoplankton & $w O 2 \operatorname{RespPhyt}=$ molO2molC $\cdot c C P$ erDW $\cdot(w D \operatorname{RespGren} W+w D \operatorname{RespBlueW}) \cdot a$ CorO 2 BOD \\
\hline Mineralization of detritus & $w O 2 M i n D e t W=\operatorname{molO} 2 \mathrm{molC} \cdot c C P e r D W \cdot w D M i n D e t w \cdot a C o r O 2 B O D$ \\
\hline Nitrification & $w O 2 N i t r W=O 2 P e r N H 4 \cdot \operatorname{molO} 2 \mathrm{molN} \cdot w N N i t r W$ \\
\hline $\begin{array}{l}\text { Chemical oxidation of hydrogen } \\
\text { sulphide }\end{array}$ & $w H 2 S O x O 2=c H 2 S O x O 2 \cdot s H 2 S W[i] \cdot s O 2 W[i] \cdot S O 2 W[i]$ \\
\hline $\begin{array}{l}\text { Oxidation of hydrogen sulphide by } \\
\text { purple sulphur bacteria }\end{array}$ & $w O 2 O x H 2 S S P B a c t=w D A s s S P B a c t W \cdot f O 2 A s s P B a c t$ \\
\hline
\end{tabular}

At low light levels in the water column or in the total absence of light, the growth of purple sulphur bacteria is limited by the concentration of oxygen and hydrogen sulphide. If the intensity of solar radiation exceeds the threshold value sLight $2[i]>$ cLight 2 Bound1, the growth of purple bacteria switches to another mechanism, and in this case, the growth is limited by light intensity and the concentration of hydrogen sulphide, and inhibited by oxygen. But if the intensity of solar radiation is more than the other threshold-sLight $2[i]>$ LLight 2 Bound 2 , the limitation of growth by radiation disappears. Mortality of purple sulphur bacteria is proportional to the constant specific mortality rate.

Detritus is formed and changed by many processes-mortality, excretion of living components, mineralization, decomposition by sulphate-reducing bacteria, consumption by zooplankton and amphipods. The mineralization of detritus is considered as the process, which depends on water temperature. The process of mineralization reduces the concentration of detritus in the lake and releases the mineral phosphorus and ammonia.

Production of oxygen by algae and cyanobacteria is defined as proportional to the increase in biomasses of these components. The concentration of oxygen increases also due to the uptake of nitrate by phytoplankton. Loss of oxygen occurs due to mineralization of detritus, respiration of phytoplankton, nitrification and oxidation of hydrogen sulphide.

The sulphate-reducing bacteria increase the concentration of hydrogen sulphide in the water layers under the chemocline. During the process of oxidation, the concentration of hydrogen sulphide decreases as well as the concentration of oxygen.

The biogenic elements-phosphorus and ammonium are released during excretion, egestion and mortality of living components and during mineralization of detritus. The uptake by phytoplankton decreases the concentrations of phosphorus and ammonium. The concentration of ammonium decreases also during the nitrification, because the 
nitrification is an important process of the nitrogen cycle in the ecosystem, leading to the transformation of ammonia to nitrate. In the model, this process is proportional to the concentration of ammonia. Temperature and oxygen conditions have an impact on nitrification.

The concentration of nitrate decreases during uptake by phytoplankton and denitrification, which is a very important process through which the ecosystem loses nitrogen. Denitrification, which is linked with the mineralization of organic matter, takes place in anaerobic conditions under the chemocline.

\section{Model parameters}

The preliminary values for each of the parameters, describing growth, mortality, respiration etc., are obtained by reviewing the literature and using own data. After this revision, two methods of sensitivity analysis were applied to the model-Morris method (Morris 1991) and FAST method (Saltelli et al. 2000). For this goal, we used the software package SIMLAB v.2.2 (2004) (Simulation Environment for
Uncertainty and Sensitivity Analysis, developed by the Joint Research Centre of the European Commission). After performing a sensitivity analysis, some of the parameters of the model were calibrated to the field data by hand. The final values of the parameters and their symbols, definitions and units are presented in Tables 14, 15, 16, 17, 18, and 19.

\section{Information about the start of the simulations and initial conditions}

The calculation starts May 15 and lasts 108 days until the end of August of the calculation year. This start date was chosen as it represents the characteristic timing of the disappearance of ice in the open water of the lake. Thus, the simulation period covers the entire summer (between the two seasonal mixing events of the upper lake water column—spring and autumn), during which period the most interesting dynamics of the reservoir take place such as the stratification of temperature and biochemical components.

The model calculates the vertical distributions for all states during the whole period except for the

Table 14 Summary of parameters for green algae and cyanobacteria (suffix Spec $=$ Gren for green algae, = Blue for cyanobacteria)

\begin{tabular}{|c|c|c|c|c|c|}
\hline \multirow[t]{2}{*}{ Symbol } & \multirow[t]{2}{*}{ Definition } & \multirow[t]{2}{*}{ Unit } & \multicolumn{2}{|c|}{ Value used } & \multirow[t]{2}{*}{ References/remarks } \\
\hline & & & $\begin{array}{l}\text { Green } \\
\text { algae }\end{array}$ & Cyanobacteria & \\
\hline cMuMaxSpec & Maximum specific growth rate & day $^{-1}$ & 1.2 & 0.8 & $\begin{array}{l}\text { Zotina (2000), Kopylov } \\
\text { et al. (2002a) }\end{array}$ \\
\hline cPDSpecMin & Minimum P/DW ratio & $\mathrm{mgP} / \mathrm{mgDW}$ & 0.0015 & 0.0025 & Janse (2005) \\
\hline cPDSpecMax & Maximum P/DW ratio & $\mathrm{mgP} / \mathrm{mgDW}$ & 0.015 & 0.025 & Janse (2005) \\
\hline cVPUptMaxSpec & Maximum P uptake capacity & $\mathrm{mgP} \mathrm{mgDW}^{-1} /$ day & 0.01 & 0.04 & Janse (2005) \\
\hline hPUptSpec & $\begin{array}{l}\text { Half-saturation } \mathrm{PO}_{4} \text { concentration } \\
\text { for uptake }\end{array}$ & $\mathrm{mg} \mathrm{l}^{-1}$ & 0.05 & 0.05 & Own data \\
\hline cNDSpecMin & Minimum N/DW ratio & $\mathrm{mgN} / \mathrm{mgDW}$ & 0.02 & 0.03 & Janse (2005) \\
\hline cNDSpecMax & Maximum N/DW ratio & $\mathrm{mgN} / \mathrm{mgDW}$ & 0.1 & 0.15 & Janse (2005) \\
\hline cVNUptMaxSpec & Maximum $\mathrm{N}$ uptake capacity & $\mathrm{mgN} \mathrm{mgDW}^{-1} /$ day & 0.07 & 0.07 & Janse (2005) \\
\hline hNUptSpec & $\begin{array}{l}\text { Half-saturation } \mathrm{N} \text { concentration } \\
\text { for uptake }\end{array}$ & $\mathrm{mg} 1^{-1}$ & 0.35 & 0.35 & Own data \\
\hline cL1B1Spec & $\begin{array}{l}\text { Light boundary "limitation-maximum } \\
\text { growth rate" }\end{array}$ & $\mathrm{W} \mathrm{m} \mathrm{m}^{-2}$ & 1 & 1 & $\begin{array}{l}\text { Kopylov et al. (2002a), } \\
\text { own data }\end{array}$ \\
\hline$c L 1 B 2 S p e c$ & $\begin{array}{l}\text { Light boundary "maximum growth } \\
\text { rate - inhibition" }\end{array}$ & $\mathrm{W} \mathrm{m} \mathrm{m}^{-2}$ & 2 & 2 & $\begin{array}{l}\text { Kopylov et al. (2002a), } \\
\text { own data }\end{array}$ \\
\hline cL1B3Spec & $\begin{array}{l}\text { Light boundary "inhibition - zero } \\
\text { growth rate" }\end{array}$ & $\mathrm{W} \mathrm{m}^{-2}$ & 5 & 5 & $\begin{array}{l}\text { Kopylov et al. (2002a), } \\
\text { own data }\end{array}$ \\
\hline cExtSpec & Light extinction constant & $\mathrm{m}^{2} \mathrm{gDW}^{-1}$ & 0.25 & 0.35 & Janse (2005) \\
\hline
\end{tabular}


Table 15 Summary of parameters for zooplankton and amphipods (suffix Spec $=$ Zoo for zooplankton, = Gamm for amphipods)

\begin{tabular}{|c|c|c|c|c|c|}
\hline \multirow[t]{2}{*}{ Symbol } & \multirow[t]{2}{*}{ Definition } & \multirow[t]{2}{*}{ Unit } & \multicolumn{2}{|l|}{ Value used } & \multirow[t]{2}{*}{ References/remarks } \\
\hline & & & Zooplankton & Amphipods & \\
\hline $\begin{array}{c}\text { kMuMaxZoo, } \\
\text { сMuGamm }\end{array}$ & $\begin{array}{l}\text { Maximum specific growth rate, } \\
\text { constant specific growth rate }\end{array}$ & day $^{-1}$ & 0.129 & 0.01 & $\begin{array}{l}\text { Temerova et al. (2002), } \\
\text { Tolomeyev et al. (2006) }\end{array}$ \\
\hline$k D \operatorname{Re} s p S p e c$ & Respiration constant & day $^{-1}$ & 0.045 & - & Own data \\
\hline cTmOptSpec & Optimum temperature & ${ }^{\circ} \mathrm{C}$ & 20 & 16 & $\begin{array}{l}\text { Gutelmacher (1986), } \\
\text { Khmeleva (1988) }\end{array}$ \\
\hline cSigTmSpec & Temperature constant & ${ }^{\circ} \mathrm{C}$ & 10 & 10 & $\begin{array}{l}\text { Gutelmacher (1986), } \\
\text { own data }\end{array}$ \\
\hline cPDSpec $\operatorname{Re} f$ & Reference P/D-ratio & $\mathrm{mgP} / \mathrm{mgDW}$ & 0.005 & 0.005 & $\begin{array}{l}\text { Jorgensen et al. (1978), } \\
\text { own data }\end{array}$ \\
\hline cNDSpec $\operatorname{Re} f$ & Reference N/D-ratio & $\mathrm{mgN} / \mathrm{mgDW}$ & 0.07 & 0.07 & Janse (2005), own data \\
\hline hDAlg Spec & $\begin{array}{l}\text { Half-saturation food } \\
\text { concentration for growth }\end{array}$ & $\operatorname{mgDW} 1^{-1}$ & 0.171 & - & Temerova et al. (2002) \\
\hline tDAlg Spec & $\begin{array}{l}\text { Threshold food concentration } \\
\text { for growth }\end{array}$ & $\operatorname{mgDW} 1^{-1}$ & 0.24 & - & Temerova et al. (2002) \\
\hline fDAssSpec & DW-assimilation efficiency & - & 0.35 & 0.35 & Janse (2005), own data \\
\hline fDissMortSpec & $\begin{array}{l}\text { Soluble nutrient fraction } \\
\text { of died Spec }\end{array}$ & - & 0.1 & 0.1 & Janse (2005), own data \\
\hline fDissEgesSpec & $\begin{array}{l}\text { Soluble nutrient fraction of by } \\
\text { Spec egested food }\end{array}$ & - & 0.25 & 0.25 & Janse (2005), own data \\
\hline
\end{tabular}

Table 16 Summary of parameters for purple sulphur bacteria

\begin{tabular}{|c|c|c|c|c|c|}
\hline \multirow[t]{2}{*}{ Symbol } & \multirow[t]{2}{*}{ Definition } & \multirow[t]{2}{*}{ Unit } & \multicolumn{2}{|l|}{ Value used } & \multirow[t]{2}{*}{ References/remarks } \\
\hline & & & $\begin{array}{l}\text { sLight } 2[i]< \\
\text { cLight } 2 \text { Bound } 1\end{array}$ & $\begin{array}{l}\text { sLight } 2[i]> \\
\text { cLight } 2 \text { Bound } 1\end{array}$ & \\
\hline kMuMaxSPBact & $\begin{array}{l}\text { Maximum specific growth } \\
\text { rate }\end{array}$ & day $^{-1}$ & 0.312 & 1.728 & $\begin{array}{l}\text { Degermendzhy et al. (2002), } \\
\text { De Wit et al. (1995) }\end{array}$ \\
\hline$y H 2 S S P B a c t$ & Yield factor $\mathrm{H}_{2} \mathrm{~S}$ a & $\mathrm{mgDW} \mathrm{mgH}_{2} \mathrm{~S}^{-1}$ & 0.17 & 0.35 & De Wit et al. (1995) \\
\hline hO2SPBact & $\begin{array}{l}\text { Half-saturation concentration } \\
\text { of } \mathrm{O}_{2}\end{array}$ & $\mathrm{mgO}_{2} 1^{-1}$ & 0.032 & - & De Wit et al. 1995 \\
\hline yO2SPBact & Yield factor $\mathrm{O}_{2}$ & mgDW mgO & 0.11 & - & De Wit et al. (1995) \\
\hline$i O 2 S P B a c t$ & $\begin{array}{l}\text { Constant of growth inhibition } \\
\text { by } \mathrm{O}_{2}\end{array}$ & $\mathrm{mgO}_{2} 1^{-1}$ & - & 0.1 & Degermendzhy et al. (2002) \\
\hline cLight 2 Bound 2 & $\begin{array}{l}\text { Light thresholds "limitation } \\
\text { - maximum growth rate" }\end{array}$ & $\mathrm{W} \mathrm{m} \mathrm{m}^{-2}$ & - & 0.6 & Degermendzhy et al. (2002) \\
\hline hH2SSPBactO2 & $\begin{array}{l}\text { Half-saturation concentration } \\
\text { of } \mathrm{H}_{2} \mathrm{~S}\end{array}$ & $\mathrm{mgH}_{2} \mathrm{~S} \mathrm{l}^{-1}$ & 0.001 & & De Wit et al. (1995) \\
\hline cLight 2 Bound 1 & $\begin{array}{l}\text { Light threshold for changing } \\
\text { of the mechanism of } \\
\text { oxidation of } \mathrm{H}_{2} \mathrm{~S}\end{array}$ & $\mathrm{~W} \mathrm{~m} \mathrm{~m}^{-2}$ & 0 & & Degermendzhy et al. (2002) \\
\hline cPDSPurpBactW & Reference P/D-ratio & $\mathrm{mgP} / \mathrm{mgDW}$ & 0.005 & & Own data \\
\hline cNDSPurpBactW & Reference N/D-ratio & $\mathrm{mgN} / \mathrm{mgDW}$ & 0.01 & & Own data \\
\hline cExtSPBact & Light extinction constant & $\mathrm{m}^{2} \mathrm{gDW}^{-1}$ & 0.1 & & Degermendzhy et al. (2002) \\
\hline
\end{tabular}


Table 17 Summary of parameters for sulphate-reducing bacteria

\begin{tabular}{|c|c|c|c|c|}
\hline Symbol & Definition & Unit & $\begin{array}{l}\text { Value } \\
\text { used }\end{array}$ & References/remarks \\
\hline iO2SRBact & Constant of growth inhibition by $\mathrm{O}_{2}$ & $\mathrm{mgO}_{2} \mathrm{l}^{-1}$ & 0.1 & Pfenning (1989) \\
\hline iH2SSRBact & Constant of growth inhibition by $\mathrm{H}_{2} \mathrm{~S}$ & $\mathrm{mgH}_{2} \mathrm{~S}^{-1}$ & 250 & Kuznetsov (1970) \\
\hline cPDSRBactW & Reference P/D-ratio & $\mathrm{mgP} / \mathrm{mgDW}$ & 0.005 & Own data \\
\hline cNDSRBactW & Reference N/D-ratio & $\mathrm{mgN} / \mathrm{mgDW}$ & 0.01 & Own data \\
\hline yOMSRBact & Food assimilation efficiency & - & 0.5 & $\begin{array}{l}\text { Degermendzhy et al. } \\
\text { (2002) }\end{array}$ \\
\hline fDissEgesSRBactWPO4 & $\begin{array}{l}\text { Soluble nutrient fraction of by sulphate-reducing } \\
\text { bacteria egested food }\end{array}$ & - & 0.25 & Own data \\
\hline fDissEgesSRBactWNH4 & $\begin{array}{l}\text { Soluble nutrient fraction of by sulphate-reducing } \\
\text { bacteria egested food }\end{array}$ & - & 0.25 & Own data \\
\hline cH2SFormSRBact & $\begin{array}{l}\mathrm{H}_{2} \mathrm{~S} \text { formation per } 1 \mathrm{mg} \text { of increment of biomass } \\
\text { of sulphate-reducing bacteria }\end{array}$ & $\mathrm{mgH}_{2} \mathrm{~S} \mathrm{mgDW}^{-1}$ & 0.51 & Truper (1989) \\
\hline
\end{tabular}

Table 18 Summary of others parameters used in the model

\begin{tabular}{|c|c|c|c|c|}
\hline Symbol & Definition & Unit & Value used & References/remarks \\
\hline fDissMortPhyt & Soluble nutrient fraction of died algae & - & 0.2 & Janse (2005) \\
\hline kDMinDetW & Decomposition constant of detritus & day $^{-1}$ & 0.01 & Janse (2005) \\
\hline$w g_{\max } D e t$ & Maximum sedimentation rate of detritus & $m$ day $^{-1}$ & 0.25 & Janse (2005) \\
\hline$T^{0}$ & Reference temperature & ${ }^{\circ} \mathrm{C}$ & 20 & Established \\
\hline$\theta_{\min }$ & Temperature constants for mineralization & $1 / \mathrm{e}^{\circ \mathrm{C}}$ & 1.07 & Janse (2005) \\
\hline$h O 2 B O D$ & Half-saturation oxygen concentration for BOD & $\mathrm{mgO}_{2} 1^{-1}$ & 1 & Janse (2005) \\
\hline NO3PerC & Mol $\mathrm{NO}_{3}$ denitrified per mol $C$ mineralized & - & 0.8 & Janse (2005) \\
\hline O2PerNO3 & $\mathrm{Mol} \mathrm{O}_{2}$ formed per mol $\mathrm{NO}_{3}$-ammonified & - & 1.5 & Janse (2005) \\
\hline $\mathrm{O} 2 \mathrm{PerNH} 4$ & $\mathrm{Mol} \mathrm{O}_{2}$ used per mol $\mathrm{NH}_{4}$ nitrified & - & 2 & Janse (2005) \\
\hline molNmolC & Ratio of molecular weights & $\mathrm{gN} \mathrm{gC}^{-1}$ & 1.1667 & Constant \\
\hline molO2molC & Ratio of molecular weights & $\mathrm{gO} 2 \mathrm{gC}^{-1}$ & 2.6667 & Constant \\
\hline $\operatorname{molO} 2 \mathrm{molN}$ & Ratio of molecular weights & $\mathrm{gO} 2 \mathrm{gN}^{-1}$ & 2.2857 & Constant \\
\hline cCPerDW & C content of organic matter & 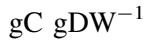 & 0.4 & Established \\
\hline cH2SOxO2 & Reaction coefficient of $\mathrm{H}_{2} \mathrm{~S}$ chemical oxidation & day $^{-1} \mathrm{~g}^{-2}$ & 0.005357 & De Wit et al. (1995) \\
\hline fPAR & The fraction of PAR & - & 0.48 & Established \\
\hline$f \operatorname{Re} f r$ & The fraction reflected at the water surface & - & 0.1 & Established \\
\hline fPart 1 & The fraction of the first spectrum in the FAR & - & 0.33 & Own data \\
\hline fPart2 & The fraction of the second spectrum in the FAR & - & 0.33 & Own data \\
\hline
\end{tabular}

biomass of amphipods. Gammarus lacustris is only present in the central part of the lake from approximately the beginning of June to the end of July. During other periods of the year amphipods live in the littoral zone of lake and do not have to be considered in the model.

Initial vertical distributions of green algae and cyanobacteria have the homogenized forms in the upper layers of the water column (it is the result of spring mixing event) and zero values under the chemocline. Zooplankton has the same homogenized initial distribution in the upper layers as green algae and cyanobacteria because it is usual event on the start date after opening of water and mixing. The amphipods appear in the beginning of June in the thin layer of water near the depth $6 \mathrm{~m}$ 
Table 19 A list of calibrated parameters

\begin{tabular}{|c|c|c|c|c|c|c|}
\hline Category & Symbol & Definition & Unit & Range & $\begin{array}{l}\text { Value } \\
\text { used }\end{array}$ & References/remarks \\
\hline \multirow[t]{5}{*}{ Green algae } & cTmOptGren & Optimum temperature & ${ }^{\circ} \mathrm{C}$ & $18-21$ & 18 & Own data \\
\hline & cSigTmGren & Temperature constant & ${ }^{\circ} \mathrm{C}$ & $5-15$ & 8 & $\begin{array}{l}\text { Prokopkin et al. (2006), } \\
\text { Janse (2005) }\end{array}$ \\
\hline & $w g_{\max }$ Gren & Maximum sedimentation rate & $\mathrm{m} \mathrm{day}^{-1}$ & $0-1$ & 0.65 & Jorgensen et al. (1978) \\
\hline & kMortGrenW & Mortality constant & day $^{-1}$ & $0.01-0.1$ & 0.01 & Own data \\
\hline & $k D$ Re spGrenW & Respiration constant & day $^{-1}$ & $0.01-0.1$ & 0.028 & Own data \\
\hline \multirow[t]{5}{*}{ Cyanobacteria } & cTmOptBlue & Optimum temperature & ${ }^{\circ} \mathrm{C}$ & $20-25$ & 21 & Own data \\
\hline & cSigTmBlue & Temperature constant & ${ }^{\circ} \mathrm{C}$ & $5-15$ & 8 & $\begin{array}{l}\text { Prokopkin et al. (2006), } \\
\text { Janse (2005) }\end{array}$ \\
\hline & $w g_{\max }$ Blue & Maximum sedimentation rate & $\mathrm{m} \mathrm{day}^{-1}$ & $0-1$ & 0.35 & Jorgensen et al. (1978) \\
\hline & kMortBlueW & Mortality constant & day $^{-1}$ & $0.01-0.1$ & 0.01 & Own data \\
\hline & $k D \operatorname{Re} s p B l u e$ & Respiration constant & day $^{-1}$ & $0.01-0.1$ & 0.011 & Own data \\
\hline Zooplankton & kMortZoo & Mortality constant & day $^{-1}$ & $\begin{array}{c}0.005- \\
0.05\end{array}$ & 0.01 & Jorgensen et al. (1978) \\
\hline Amphipods & kMortGamm & Mortality constant & day $^{-1}$ & $\begin{array}{c}0.0005- \\
0.005\end{array}$ & 0.001 & Own data \\
\hline \multirow{3}{*}{$\begin{array}{l}\text { Sulphate- } \\
\text { reducing } \\
\text { bacteria }\end{array}$} & kMuMaxSRBact & Maximum specific growth rate & day $^{-1}$ & $\begin{array}{l}0.1- \\
0.432\end{array}$ & 0.17 & $\begin{array}{l}\text { Degermendzhy et al. } \\
\text { (2002), own data }\end{array}$ \\
\hline & kMortSRBactW & Mortality constant & day $^{-1}$ & ${ }^{0-}$ & 0.04 & $\begin{array}{l}\text { Degermendzhy et al. } \\
\text { (2002) }\end{array}$ \\
\hline & hOMSRBact & $\begin{array}{l}\text { Half-saturation concentration } \\
\text { of detritus }\end{array}$ & $\operatorname{mgDW~} 1^{-1}$ & $0-5$ & 3 & Own data \\
\hline \multirow[t]{2}{*}{$\begin{array}{l}\text { Purple sulphur } \\
\text { bacteria }\end{array}$} & kMortSPBact & $\begin{array}{l}\text { Mortality constant } \\
\quad(\text { sLight } 2[i]<\text { cLight } 2 \text { Bound } 1)\end{array}$ & day $^{-1}$ & $0.01-0.1$ & 0.04 & Own data \\
\hline & kMortSPBact & $\begin{array}{l}\text { Mortality constant } \\
\quad(\text { sLight } 2[i]>\text { LLight } 2 \text { Bound } 1)\end{array}$ & day $^{-1}$ & $0.01-0.1$ & 0.02 & Own data \\
\hline \multirow[t]{10}{*}{ Others } & $\theta_{\text {sed }}$ & $\begin{array}{l}\text { Temperature constant of } \\
\text { sedimentation }\end{array}$ & $1 / \mathrm{e}^{\circ \mathrm{C}}$ & $\begin{array}{r}1.01- \\
1.20\end{array}$ & 1.16 & Own data \\
\hline & $\theta_{\text {nitr }}$ & $\begin{array}{l}\text { Temperature constants } \\
\text { for nitrification }\end{array}$ & $1 / \mathrm{e}^{\circ} \mathrm{C}$ & $\begin{array}{r}1.02- \\
1.10\end{array}$ & 1.02 & Own data \\
\hline & $k N i t r W$ & Nitrification rate constant & day $^{-1}$ & $\begin{array}{c}0.001- \\
0.15\end{array}$ & 0.003 & Own data \\
\hline & hO2Nitr & $\begin{array}{l}\text { Half-saturation } \mathrm{O}_{2} \\
\text { concentration for nitrification }\end{array}$ & $\mathrm{mgO}_{2} 1^{-1}$ & $0-2$ & 0.01 & Own data, Janse (2005) \\
\hline & hNO3Denit & $\begin{array}{l}\text { Half-saturation } \mathrm{NO}_{3} \\
\text { concentration for } \\
\text { denitrification }\end{array}$ & $\mathrm{mgNO}_{3} 1^{-1}$ & $0-0.2$ & 0.002 & Own data, Janse (2005) \\
\hline & $c E x t W a t$ & Light extinction by water & $\mathrm{m}^{-1}$ & $0.1-1$ & 0.5 & $\begin{array}{l}\text { Own data, Prokopkin } \\
\text { et al. (2006) }\end{array}$ \\
\hline & cExtDet & Light extinction by detritus & $\mathrm{m}^{2} \mathrm{gDW}^{-1}$ & $\begin{array}{c}0.075- \\
0.15\end{array}$ & 0.1 & Own data, Janse (2005) \\
\hline & cPBackLoad & Background P loading & $\mathrm{g} /\left(\mathrm{d} \mathrm{m}^{2}\right)$ & $0-0.005$ & 0.0003 & Own data \\
\hline & cNBackLoad & Background $\mathrm{N}$ loading & $\mathrm{g} /\left(\mathrm{d} \mathrm{m}^{2}\right)$ & $0-0.05$ & 0.0009 & Own data \\
\hline & cH2SBottomLoad & $\begin{array}{l}\mathrm{H}_{2} \mathrm{~S} \text { loading from } \\
\text { the sediments }\end{array}$ & $\mathrm{g} /\left(\mathrm{d} \mathrm{m}^{2}\right)$ & $0.1-2$ & 1.1 & Own data \\
\hline
\end{tabular}

(Tolomeyev et al. 2006). Initial vertical distributions of bacteria, oxygen, hydrogen sulphide and nutrients have uneven complex forms as the result of availability of the monimolimnion in the lake. All initial values are defined on the field data (unpublished). 


\section{Sensitivity analysis}

Short description of the methods

Sensitivity analysis is an important first step in the model analysis, and shows which parameters and input factors have the most influence on the model results (Janse 2005). In our case for this estimation we have used a two-step sensitivity analysis-first Morris method (Morris 1991) and then FAST method (Saltelli et al. 2000). We used the Morris method in order to make a rough selection of the parameters that control most of the output variability, with a relatively low computational effort (Saltelli et al. 2000). After this step, the FAST method is applied to the subset of parameters found by the Morris method. The FAST method is well suited for non-linear or non-monotonic models and allows one to obtain the variance of in model predictions, and the contribution of individual input factors to this variance (Janse 2005).

Results of sensitivity analysis

In the first step, the 102 model parameters-this the full set only without those parameters which are exact constants (e.g. molNmolC)—were ranked by the instrumentality of Morris method. As model outputs of interest, we have used the maximum concentrations and the depths of maximum concentrations of model variables. Together, these are the main features described the form of vertical distributions of model variables. Table 20 shows the top- 10 of most sensitive parameters for several main model outputs: for green algae and cyanobacteria, for phosphorus as example of nutrients and for hydrogen sulphide as example of the others variables in the model.

Some of the outcomes of the sensitivity analysis are easy to understand. The maximum concentration of phosphorus is affected most by the background loading cPBackLoad and growth parameters of phytoplankton: cSigTmBlue and cL1B1Gren. The depth of peak biomass of green algae is influenced by max sedimentation rate $w g_{\max }$ Gren mainly. Hydrogen sulphide loading from the sediments cH2SBottomLoad primary affect the maximum concentration of it. Most model outputs are influenced by a large number of parameters from the processes

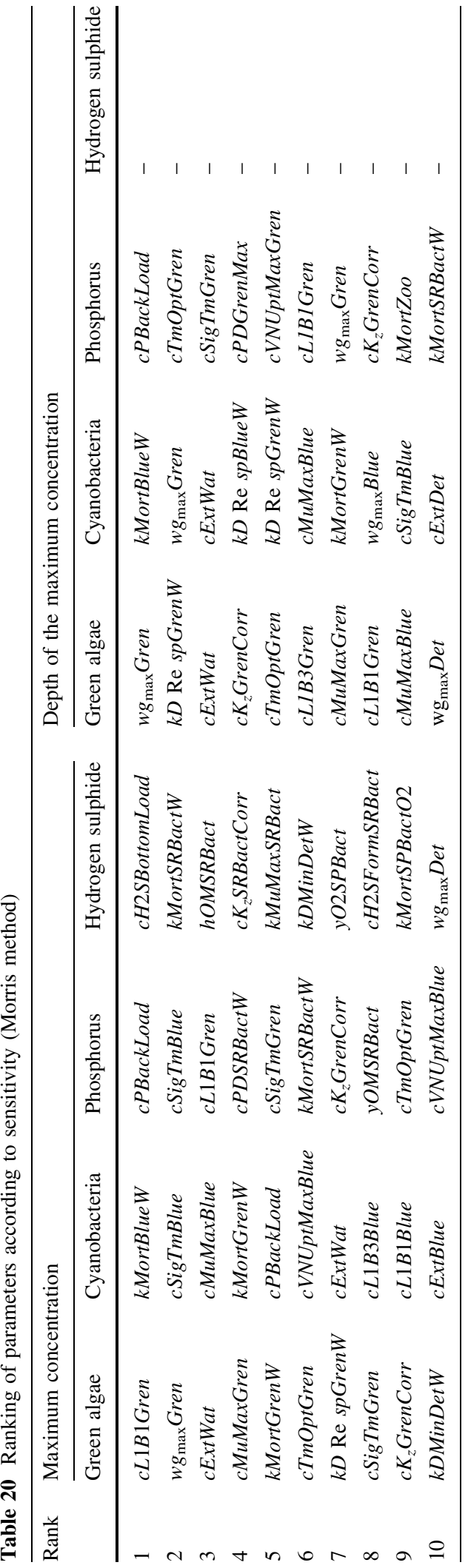


directly affecting this variable. But there are the exceptions. The depths of the maximum concentration of hydrogen sulphide (Table 20) and ammonium (not presented data) are not influenced by all model parameters. This means that irrespective of the model input, the depth of maximum concentration will be the same. In the case of hydrogen sulphide and ammonium, this depth will equal the maximum depth of the lake. There are also model outputs which are influenced by not only the parameters directly associated with it but also by parameters that play a role in others parts of the model. For example, the most sensitive parameters for the outputs associated with cyanobacteria include the parameters for green algae: kMortGren $W, k D$ Re spGren $W, w g_{\max }$ Gren. It means that there are the different direct and indirect interactions occurring in the model inside the phytoplankton community.

After the Morris method, a subset including 24 most influential parameters was selected and analysed by FAST method (Saltelli et al. 2000). Figure 1 shows the results of this method applied to several model outputs: maximum concentration and the depth of max concentration of green algae, maximum concentration of hydrogen sulphide and maximum concentration of phosphorus. The more obvious effects discussed earlier still hold, e.g. maximum concentration of phosphorus is affected by the background loading cPBackLoad or maximum sedimentation rate of green algae $w g_{\max }$ Gren mainly influence on the position of the peak its biomass in the water column. But these results now have more quantitative character.

The main result obtained with this two-step sensitivity analysis is a subset of parameters which have strongest impact on the model results. This subset contains the parameters describing lake features and environment (e.g. cH2SBottomLoad and cPBackLoad) and also parameters of different variables and processes in the lake. In accordance with
Fig. 1 FAST total-order effects of the subset of parameters on the several model outputs, scaled to $100 \%$. The model outputs and parameters are explained in the text

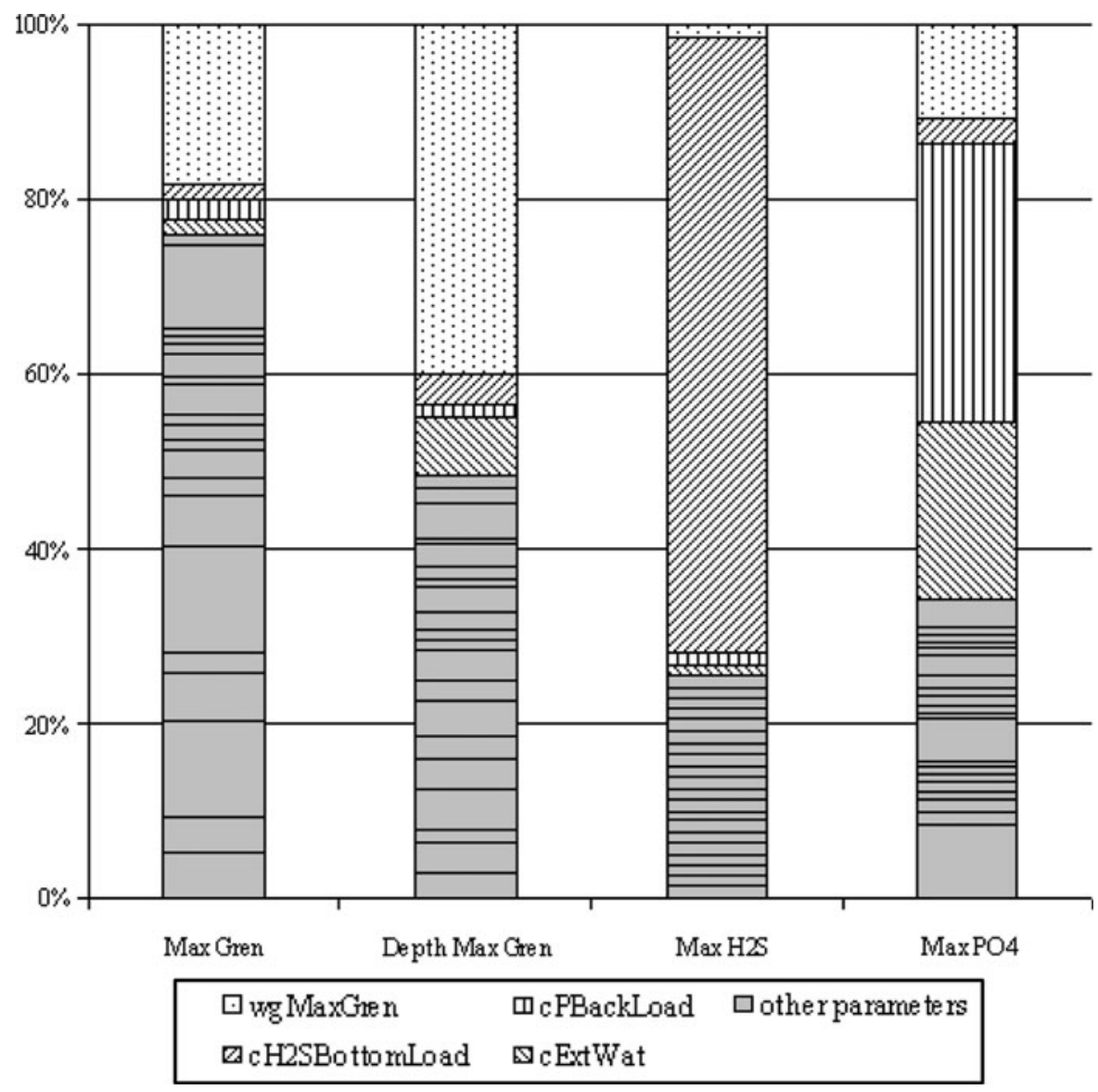


the literature, most of these parameters are variable in nature and therefore demand further calibration.

\section{Calibration of the model}

Short description of the procedure

After the sensitivity analysis, the model was calibrated to the field data by hand, on basis of a visual comparison of model calculation and field data.

In this procedure, we used the available (generally unpublished) field data from years 1999 to 2001. The values of external physical parameters-cloud, intensity and direction of wind, air temperature, etc.were taken for the available year 2002. This year was chosen also as the year with characteristic weather conditions, without lengthy weather anomalies.

We focused on field data collected in July that is in the middle of the summer season, because in this time the stable stratifications of biological and chemical states are present in the lake. For this reason, the simulations have been carried out 62 days from May 15 to July 15 . The vertical distributions of the main model variables were calculated and compared with the available observations. The final values of the calibrated parameters and also their symbol, definition, range and references/remarks are presented in Table 19.
Results of calibration of the model

The results of the simulation after model calibration in comparison with the available field observations are shown in Figs. 2, 3 and 4.

The results of the vertical distributions of green algae, cyanobacteria and zooplankton in the water column are shown in Fig. 2. The green algae have a deep peak of biomass in both the calculations as well as in the field observations. Cyanobacteria also forms deep peak of biomass, which is located above the peak of biomass of green algae. The maximum values of biomasses of modelled species are in good agreement with the field data. The model description of the vertical profile of zooplankton is not quite correct.

The vertical distributions of oxygen, hydrogen sulphide and sulphate-reducing bacteria in the model and field observations are shown in Fig. 3. The calculated concentration of oxygen in the nearsurface layer is in agreement with field data-near $9 \mathrm{mg}^{-1}$ in the middle of July. The maximum depth of oxygen zone (about $13 \mathrm{~m}$ ) also coincides well with the field data. Both in the field data and in calculations, there is deep peak of oxygen concentration.

The distribution of hydrogen sulphide in the calculations is in good agreement with the field data. The concentration near the bottom equals $25-30 \mathrm{mg} / \mathrm{l}$ both in the model and in the observations. The position of the chemocline as the interface of oxygen
Fig. 2 The vertical profiles of phytoplankton and zooplankton in the middle of July. The lines are the model calculations. The triangles are the field observations (Gaevsky et al. 2002 and unpublished data)
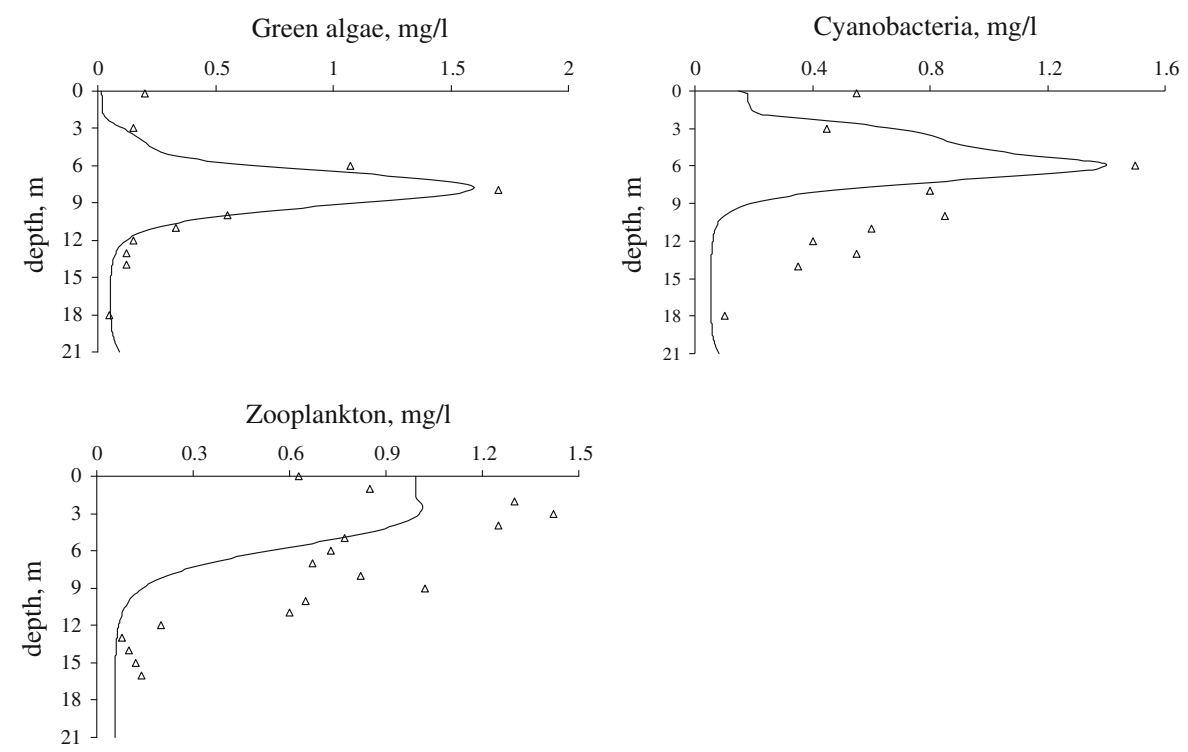
Fig. 3 The vertical profiles of oxygen, hydrogen sulphide and sulphatereducing bacteria in the middle of July. The lines are the model calculations. The triangles are the field observations (unpublished data)
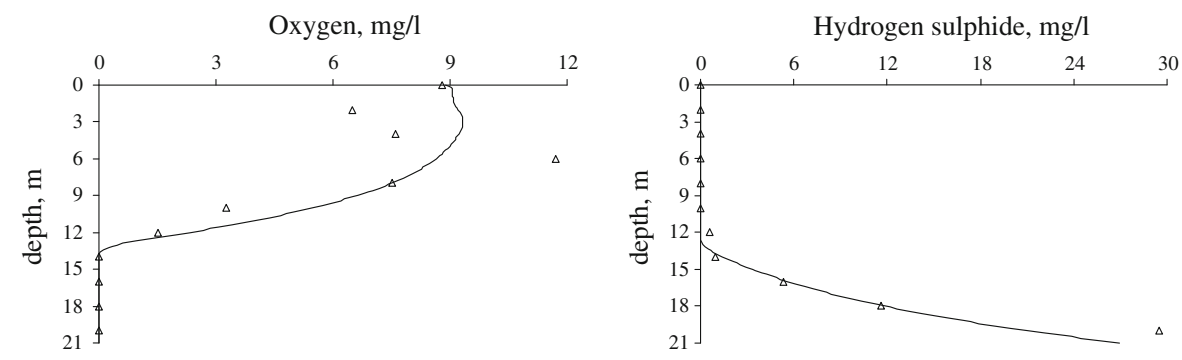
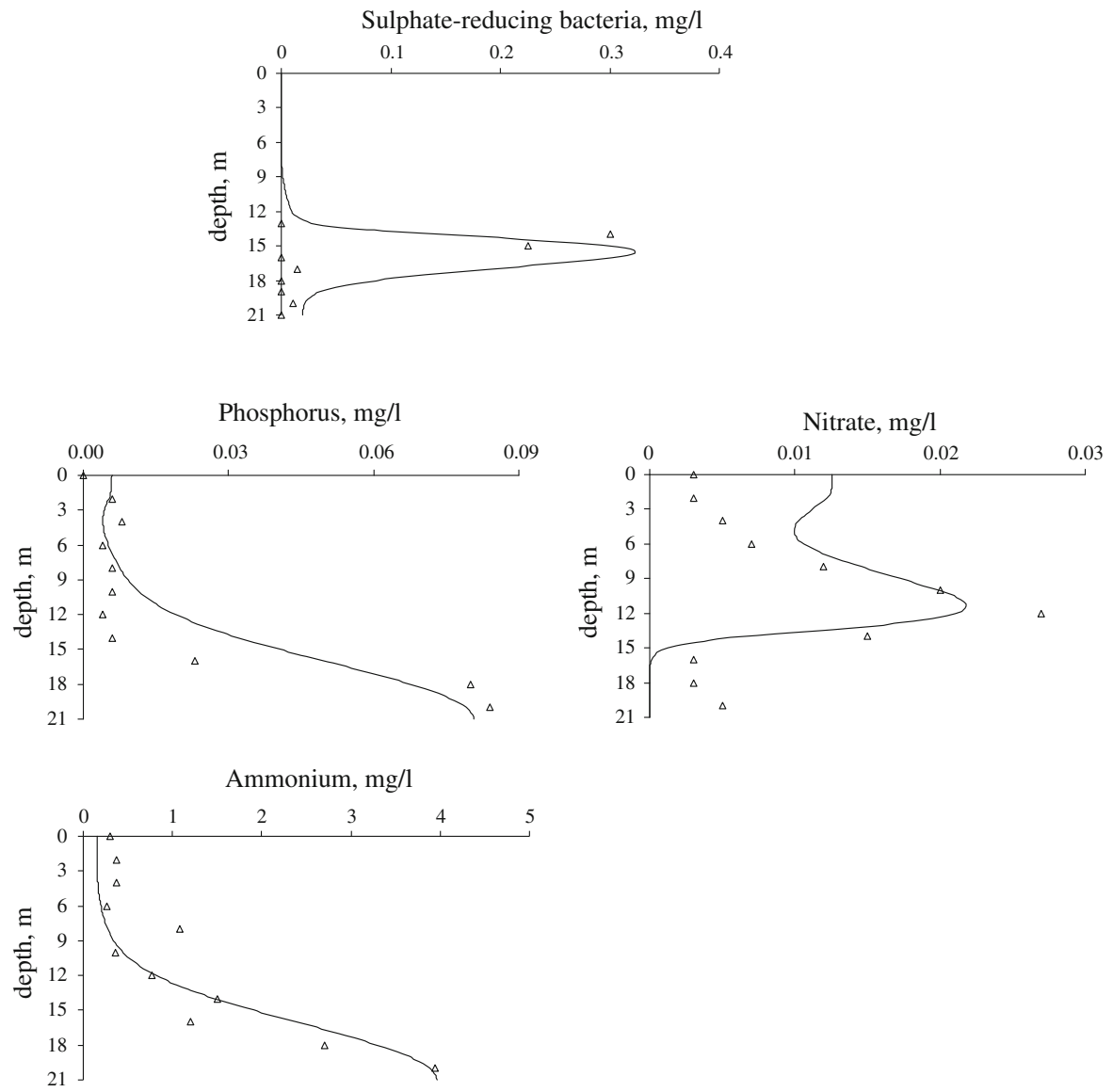

Fig. 4 The vertical profiles of nutrients in the middle of July. The lines are the model calculations. The triangles are the field observations (unpublished data)

and hydrogen sulphide is the same in the calculations and the observations. The maximum biomass of sulphate-reducing bacteria in the simulations coincides with field data, but the position of the peak is lower.

The calculations and field data of the vertical distributions of nutrients in the water column are presented in Fig. 4. The main feature of vertical distribution of mineral phosphorus and ammonium is the accumulation of these substances in the water column near the bottom in the model and the observations. Above the chemocline, the distributions of mineral phosphorus and ammonium are approximately uniform. The maximum concentration of nitrate is a little higher the chemocline near depth $12 \mathrm{~m}$. Under the chemocline, the concentration of nitrate is close at minimum in the calculations and the observations.

For the vertical distributions of the amphipods, purple sulphur bacteria and detritus (Fig. 5), a direct comparison with field data is not possible in absence of 
Fig. 5 The vertical profiles of the amphipods, purple sulphur bacteria and detritus in the middle of July. The lines are the model calculations
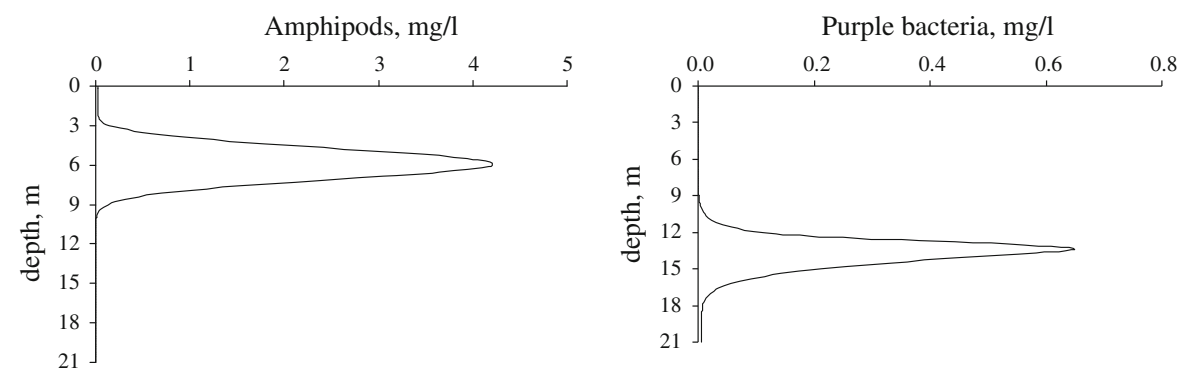

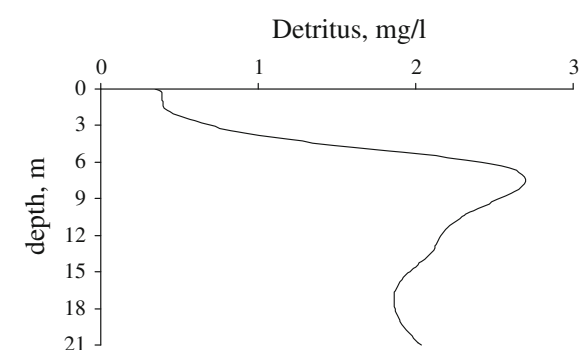

field data. From the paper of Tolomeyev et al. (2006), we know that the amphipods appear in the thin layer of water near the depth $6 \mathrm{~m}$ with a comparable biomass as in the calculations. The peak of the biomass of purple sulphur bacteria is often located in the chemocline (Pimenov et al. 2003). The same pattern occurs in the simulations. There is no field data about vertical distributions of the detritus but the modelled shape of the profile seems plausible.

As result of the calibration of the model, there is a good match between the model description of the vertical distributions of the main variables and the available field data. But of course, there are also mismatches between model and data. For example, zooplankton has a more complicated vertical distribution in the lake than in the model. It seems that it is due to the complicated sex and age structure of the zooplankton populations and the restrictions set by using the differential equations approach in this case. In particular, the different instars of zooplankton occupy different habitats in the water column (Zadereev and Tolomeyev 2007) and it is difficult to reproduce this in an unstructured the model based on differential equations. For these aspects of zooplankton, it seems that the application of the individualbased approach is more appropriate than differential equations with diffusion.

Also we observe the differences in the position and abundance of the peak concentration of oxygen between the model and the data. It seems that these differences are due to the fact that in the model this peak is formed only by two species of algae, but in the lake by the whole phytoplankton community comprising many species (Gaevsky et al. 2002). We hypothesize that if we add to the model additional species of algae in the future, the profile of oxygen will improve.

\section{Validation of the model}

For the model validation, we extended the comparison between model and data over a longer period than that used during calibration. The question was can the model describe the observed changes in the water ecosystem after mid-July? For validation we used published data about the profiles of phytoplankton in the August (Gaevsky et al. 2002).

In middle of July green algae and cyanobacteria form the peaks of biomass near the depths 6-8 m (Fig. 2). But already in the beginning of August the peak of biomass of cyanobacteria is below $8 \mathrm{~m}$ and peak of green algae near $10 \mathrm{~m}$ (Fig. 6). In addition, the maximum biomass of cyanobacteria increases during season, but the maximum biomass of green algae conversely decreases after July. The change of dominant species is primarily due to the differences of temperature dependence of growth of green algae and cyanobacteria. Cyanobacteria are more thermophilic, and hence their massive growth begins later than that of green algae. The reasons of changing the 

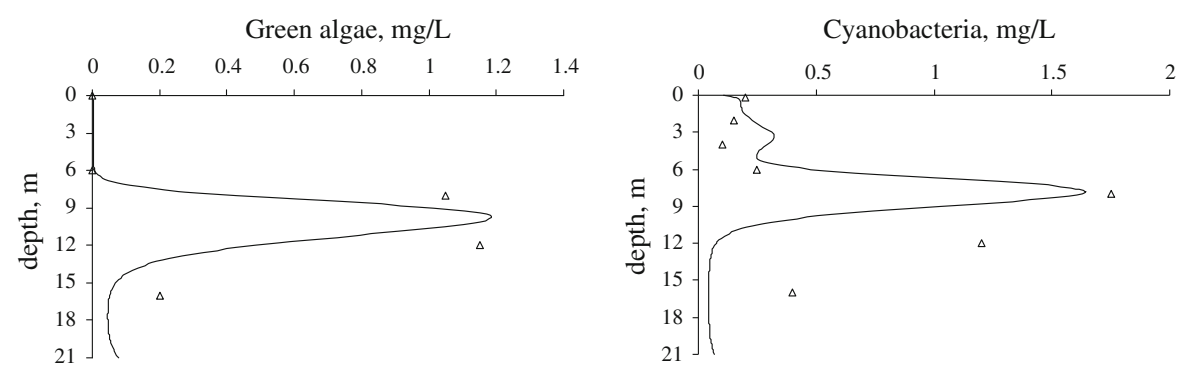

Fig. 6 The vertical profiles of green algae and cyanobacteria in August 6. The lines are the model calculations. The triangles are the field observations (Gaevsky et al. 2002)

positions in the water depth will be discussed in the next paragraph.

All these changes in the profiles of phytoplankton species are well reproduced by the model. The maximum biomasses of green algae and cyanobacteria are the same in the simulations and the field observations. The positions of the peaks are also corresponding. As a result of the calibration and validation of the model, we can conclude that the model can give a fairly good representation of dynamics in the lake during summer season, and in particular, for the vertical distribution of phytoplankton. It is, therefore, warranted to use this model for the analysis of the mechanisms responsible for the formation of the vertical heterogeneity in Lake Shira.

\section{Theoretical aspects of the formation of the vertical heterogeneity in the Lake Shira}

One of the main features of the limnology of Lake Shira lies in the stratification of temperature, chemical and biological components during summer season. It seems that the using the current model, we can investigate the mechanisms responsible for the formation of this vertical heterogeneity in the lake. To do so, we singled out key components and main processes and checked its impact on model outcome in comparison with the field observations.

All components without phytoplankton

Different variables have different vertical profiles in the summer season. Some of these variables have more or less stable vertical distributions. For example, ammonium and phosphorus during whole summer season have maximum concentrations near the bottom (Fig. 4) (Kalacheva et al. 2002). It is the result of the accumulation of these substances in this layer of water during a long time. In turn, such accumulation is the result of the absence of the consumers of nutrients in the anaerobic zone under the chemocline and the decomposition of the detritus in these layers. Above the chemocline, the distributions of mineral phosphorus and ammonium are approximately uniform, which is the result of intensive turbulent mixing in the near-surface layers of water, and usually have minimum values as the result of the consumption by phytoplankton.

The vertical distribution of nitrate is formed generally by nitrification and denitrification processes. The maximum concentration of nitrate is near depth $12 \mathrm{~m}$ - a little higher the chemocline because it is the place of maximum intensity of nitrification in the water column (Fig. 4). Under the chemocline, the concentration of nitrate is close to minimum in the calculations and the observations because the denitrification has a maximum intensity here and the system therefore loses nitrogen in this zone.

Oxygen and hydrogen sulphide are distinctly stratified with the depth (Fig. 3). The maximum oxygen concentration is observed in the 6- to $8-\mathrm{m}$ layer in field observation (Kalacheva et al. 2002) and in the 3- to 6-m layer in the simulation (Fig. 3), but in any case this zone is characterized by highly photosynthetic activity. The profile of oxygen concentration suggests that the aeration plays a key role in the distribution of oxygen at small depths near the surface of water. The anaerobic zone in the middle of summer lies below 13-14 m depth and contains high concentration of hydrogen sulphide. The maximum concentration of sulphide is near maximum depth of water column as result of the presence of the flux this substance from the bottom (Fig. 3). 
The vertical distributions of the bacteria are defined by the role which bacteria play in the ecosystem. Purple sulphur bacteria oxidizes hydrogen sulphide and as result forms a sharp peak of biomass in the chemocline - the place where the oxygen and hydrogen sulphide interact (Fig. 5). The role of sulphate-reducing bacteria in the lake is the decomposition of organic matter. This process occurs in the absence of oxygen. Therefore, the peak of biomass of sulphate-reducing bacteria is located in the water column under the chemocline in the calculations and the observations (Fig. 3). When the position of the chemocline changes, the position of peak biomass of bacteria can change too.

The amphipods Gammarus lacustris forms a narrow peak of biomass at the depth $6 \mathrm{~m}$ (Fig. 5), that agrees with field data (Tolomeyev et al. 2006). However, the pelagic zone is not typical habitats for Gammarus. The reasons on which the amphipods appear in this time in the narrow layer of water are not until well known. There is the opinion that the amphipods population appears in this zone for feeding in the beginning of June and disappears in the end of July. We suppose in the model that during this period Gammarus consumes the seston (in our model it is the sum of biomasses of green algae, cyanobacteria and detritus). But because of low growth and consumptions rates (Table 15), amphipods do not have a deep impact on vertical distributions of the seston components that is possible to estimate by using of the current model. The vertical distribution of detritus is mainly formed by a lot of different processes. At greater length in the top part of water column the processes of accumulation and formation of detritus prevail. In the bottom part of water column, the detritus is decomposed generally. It leads to decreasing detritus concentrations under the chemocline (Fig. 5). A small peak in detritus concentration near the bottom is the result of settling of detritus. The aspects of the formation of the vertical profiles of phytoplankton species are considered in the next paragraph.

Theoretical aspects of the formation of the vertical profiles of phytoplankton species

The general trends of the development of phytoplankton community during summer season have the following features. The dominant species which are green algae Dictyosphaerium tetrachotomum and cyanobacteria Lyngbya contorta (Gaevsky et al. 2002) form the deep peaks of their biomasses. The maximum biomass of green algae is observed in July usually near the depth $8 \mathrm{~m}$ and in August at 10-12 m (Gaevsky et al. 2002). The peak of cyanobacteria lies generally above the peak of green algae: in July near $6 \mathrm{~m}$ and in August near 8-9 m of the depth (Gaevsky et al. 2002). The maximum biomass of green algae in the middle of summer season exceeds the maximum biomass of cyanobacteria, but already in August the condition is opposite. Thus, during summer season, the change of the dominant species and their positions in the water column are the usual observations. The current model can reproduce these general trends of the development of phytoplankton community well (Figs. 2, 6).

Analysis with the earlier model (Degermendzhy et al. 2002) already resulted in a preliminary explanation of the mechanism responsible for the forming of the deep peaks of these species in the water column. But the facts that either of the species could become dominant and that their vertical positions varied were not explained properly, and the reasons for the occurrence of these events in the ecosystem were not clear enough. To a large extent, all processes and factors which are taken into account in the model for phytoplankton can be the causing factor for the observed events in the community. A full list of factors should include effect of the light, nutrients and temperature on the growth, mortality, respiration, consumption by zooplankton and amphipods and sedimentation of the green algae and cyanobacteria.

We can directly exclude mortality from consideration. The mortality of phytoplankton species is defined in our model as a constant, and therefore, mortality is unlikely to cause the change in dominant species and the change of their vertical positions. This assumption is confirmed by the calculations in which mortality was switched off (Fig. 7). In this case, only the expected increase in the biomasses is occurred. The changes of the dominant species and the positions are remained. It means that other processes and factors generate these changes.

The process of respiration is defined as the product of constant specific rate and temperature function, which means the reduction of the respiration at low temperature of water. The calculation in which respiration of green algae and cyanobacteria was 
Fig. 7 The modelled vertical profiles of green algae (thick line) and cyanobacteria (thin line). The left panels show the results for July 15, the right panels for August 6. The top panels show results obtained without mortality of phytoplankton, the lower panels show the results obtained without respiration of phytoplankton
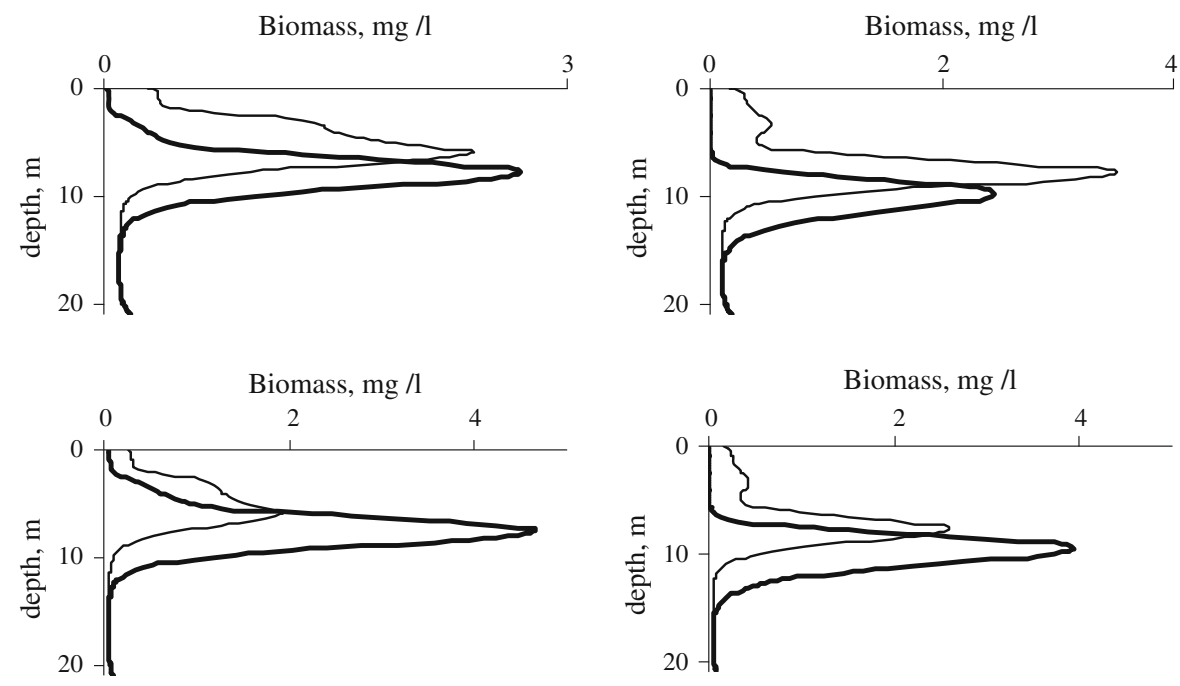

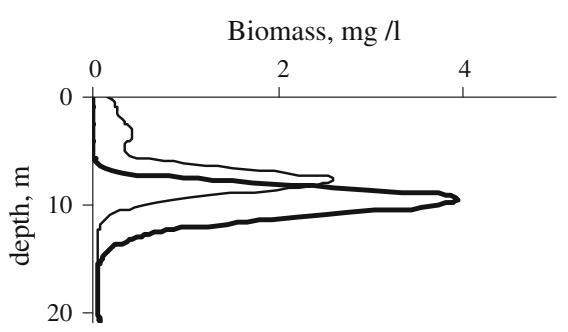

switched off shows that the changing of the dominant species is not occurred. Green algae are dominant during whole summer season (Fig. 7). But there is the change of vertical positions in both green algae and cyanobacteria. Thus, the process of respiration can be only a partial explanation for the succession of the species.

The consumption of green algae and cyanobacteria by the amphipods is not likely to be the reasons of these changes either. The calculations with the amphipods and without them do not show significant differences (Figs. 2, 6, 8). The reasons of such a weak impact of Gammarus are most likely that (a) the amphipods are present at central part of the lake approximately only during July; (b) the amphipods accumulate in the narrow layer in the water column near $6 \mathrm{~m}$; (c) growth and consumptions rates of the amphipods have low values (for example, $c M u$ Gamm $=0.01 \mathrm{day}^{-1}$ ).

The model simulations of vertical distributions of green algae and cyanobacteria with zooplankton Arctodiaptomus salinus and without it show the strong effect of zooplankton on the profiles of phytoplankton (Figs. 2, 6, 8). In the simulation without zooplankton, the maximum biomass of cyanobacteria in July exceeds the biomass of green algae. It is evidence that trophic pressure exerted by zooplankton (or its absence) can be one of the reasons of the succession (or its absence) in the phytoplankton community.
Fig. 8 The modelled vertical profiles of green algae (thick line) and cyanobacteria (thin line). The left panels show the results for July 15, the right panels for August 6. The top panels show results obtained in absence of the trophic pressure exerted by amphipods, the lower panels show the results obtained in absence of trophic pressure exerted by zooplankton
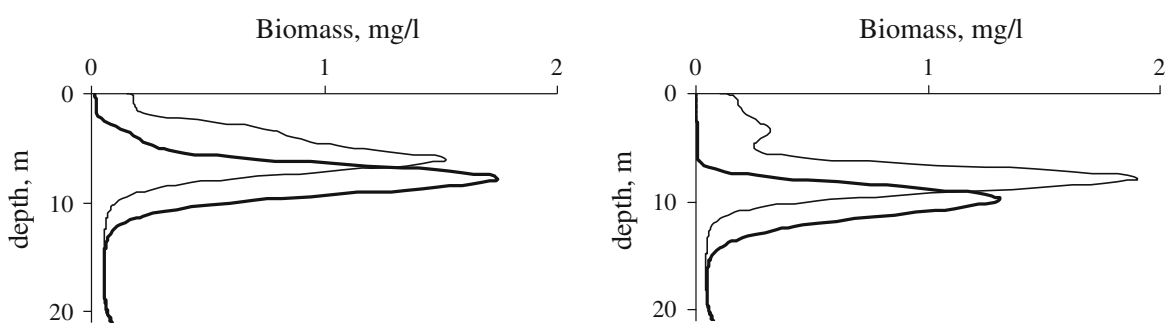

Biomass, mg/l

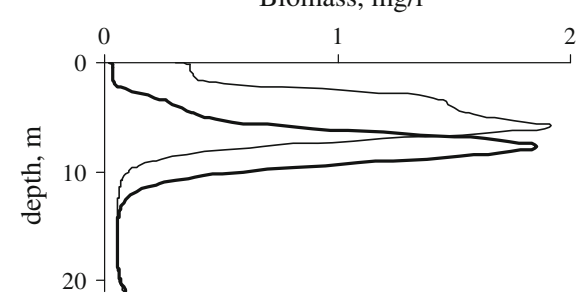


Green algae and cyanobacteria in current model have identical light function of growth rate aLLimSpec. It is assumed that both species are shaderequiring and have the maximum of photosynthetic activity when light equals $1-2 \mathrm{~W} \mathrm{~m}^{-2}$. Higher level of light inhibits the growth of green algae and cyanobacteria. In the model presented here, the intensity of solar radiation, weakened by the atmosphere and falling on the surface of the lake, has a seasonal and diurnal rhythm. During the night, this intensity has value approximately equals zero. The light intensity is increased from early morning to zenith and decreased during second part of the day. It leads to the regular changes of the shape and values of the light field in the water column.

The vertical profile of the light function aLLimBlue at different hours during July 15 is shown in Fig. 9. It is clear that the zone of optimum light conditions for growth changes position during the
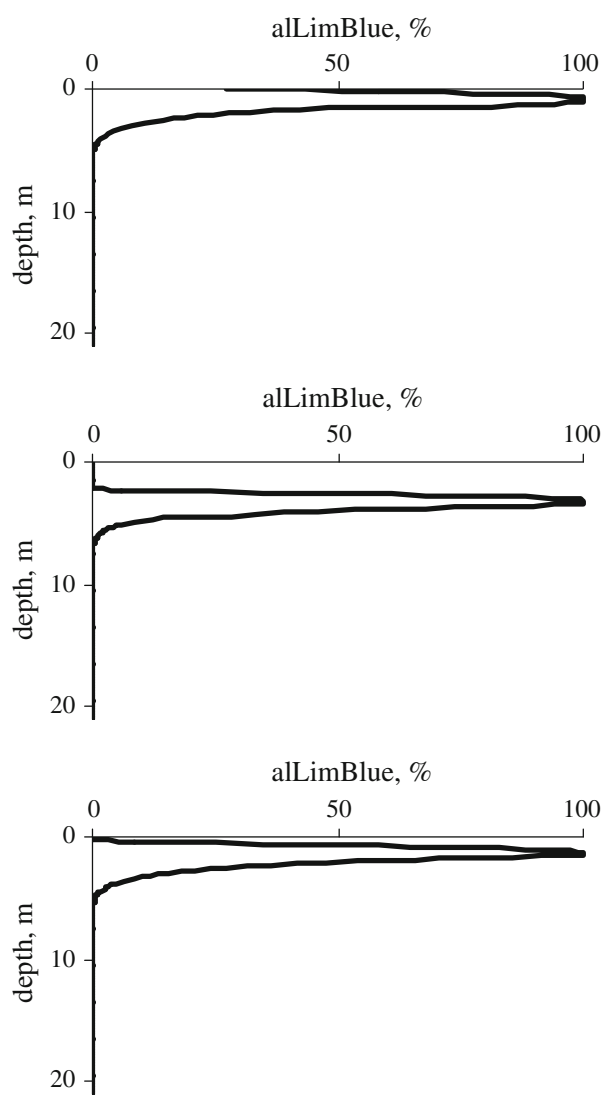

Fig. 9 The calculated profile of function aLLimBlue at July 15 at 7:00 a.m. (top panel), noon (middle panel), and 9:00 p.m. (lower panel) day. This zone lies in near-surface layers of water column during large part of the day (during night, morning and evening) and only at zenith penetrates into the deeper water. This makes it unlikely that the light conditions are the cause of the settling of phytoplankton biomasses. Also the light function is not likely to be the cause of the changing of the dominant species because this function is the same for both green algae and cyanobacteria and creates the equal light conditions for them.

A more likely cause of observed changes in phytoplankton community is the influence nutrients on the growth rate of green algae and cyanobacteria. Assume that during summer season, algae and cyanobacteria try to leave the zone with low nutrient concentrations in upper layers of water column. In this case, there is only one direction of movementto the deeper water where the concentration of nutrients is high.

When we define the value of the function aNutLimSpec to be equal to a value of 1 throughout the depth, this means that there is no nutrient limitation for green algae and cyanobacteria, and nutrient conditions are favourable for growth at any depth. In this case, the movement of phytoplankton to the deep water must disappear because the cause of the settling is absent. Vice versa the phytoplankton can shift to near-surface water because light and temperature conditions are favourable for growth in these layers.

The calculations show that when aNutLimSpec $=1$ the biomass of green algae has high value that is never observed in the lake (Fig. 10), as a result of the absence of nutrient limitation. But against our expectation, there is the settling of algae. We can assume that succession may be caused by nutrient limitation, while sedimentation occurs due to other reasons.

Cyanobacteria are more thermophilic than green algae. This phenomenon is defined in the model by cTmOptBlue $=21^{\circ} \mathrm{C}$ and cTmOptGren $=18^{\circ} \mathrm{C}$. Most likely, the difference of optimum temperatures is the cause of the formation maximum peak of cyanobacteria only in the end of summer season after the peak of green algae. When we suppose that cyanobacteria are less thermophilic than green algae the result of simulation is mass growth of cyanobacteria during whole summer, but the position of green algae is lower (Fig. 10). Also both peaks move to 
Fig. 10 The model calculations of vertical profiles of green algae (thick line) and cyanobacteria (thin line). The left panels show the results for July 15, the right panels for August 6. The top panels show the results for aNutLimSpec $=1$. Middle panels for $c$ TmOptSpec $=21^{\circ} \mathrm{C}$ for green algae and cTmOptSpec $=18^{\circ} \mathrm{C}$ for cyanobacteria. The lower panels show the results when for

$w g_{\max }$ Spec $=0 \mathrm{~m} \mathrm{day}^{-1}$ for both green algae and cyanobacteria
Biomass, mg/l

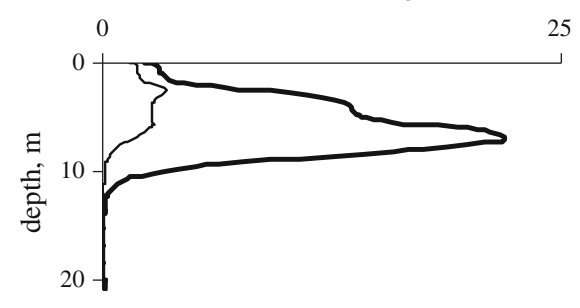

Biomass, mg/l

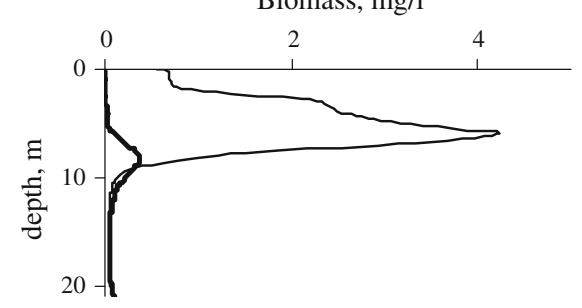

Biomass, mg/l

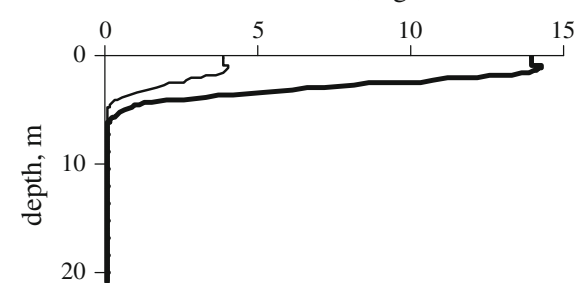

Biomass, mg/l
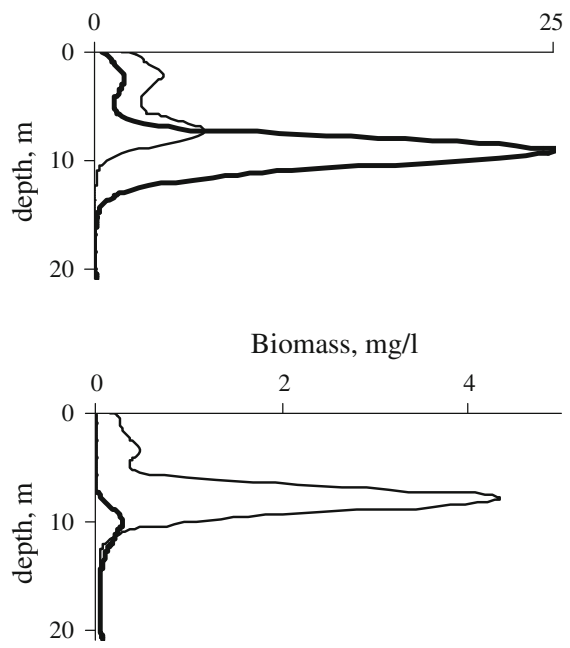

Biomass, mg/l

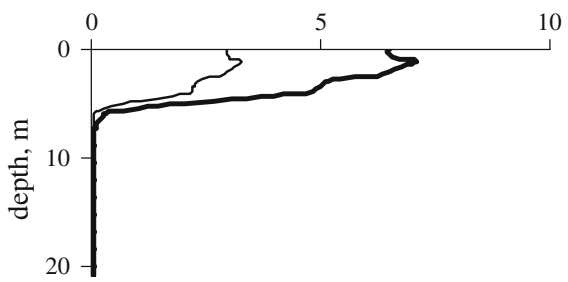

deep layers of water during season. Thus, temperature can be seen as the cause of succession of the species but is not the cause of sedimentation.

The positions of the peak biomasses in the water column are sensitive to the values of maximum sedimentation rate $w g_{\text {max }}$ Spec. We conclude this on basis of the result obtained during the test simulations which are presented in the next paragraph.

If we suppose that $w g_{\max }$ Spec $=0$ for both algae and cyanobacteria, we obtain the results that are presented in Fig. 10. It follows from this figure that when the rates of sedimentation equal zero, green algae and cyanobacteria take the positions in the near-surface layers of water where light and temperature conditions are favourable for growth. Also green algae are the dominant species during whole summer season, and there is not the change of dominant in phytoplankton community. As a result, we can draw the conclusion that sedimentation is a key process which defines the positions of peak biomasses in the water column and the cause of succession of species.

The other evidence for the significance of sedimentation for the formation of vertical distribution of biomasses in the water column is in the results of sensitivity analysis (Table 20). For example, the position of maximum biomass of green algae in the water column is strongly affected by the maximum sedimentation rate of its. After the calibration, the parameters $w g_{\max }$ Spec have the values: $0.65 \mathrm{~m}$ day $^{-1}$ for green algae and $0.35 \mathrm{~m} \mathrm{day}^{-1}$ for cyanobacteria that are in the literature range $0-1 \mathrm{~m} \mathrm{day}^{-1}$ (Jorgensen et al. 1978).

Summing up the discussion, we can conclude that the change of dominant species in phytoplankton community during summer may occurs in response to temperature and nutrient factors, trophic pressure exerted by zooplankton and the difference in the values of respiration rates of green algae and cyanobacteria. The change of the vertical positions is first of all the result of sedimentation of both species under gravitational force.

\section{Discussion}

This paper presents a general 1-D vertical ecosystem model of Lake Shira with a focus on the pelagic zone 
and summer conditions. The main innovations of this model, in the comparison earlier model (Degermendzhy et al. 2002) are in the structure of the biological components in the model and the way the different ecosystem processes are modelled. In general, the resulting calculations are in good agreement with observations on the vertical distribution of most components in the lake. We made this judgment on basis of a comparison of the main characteristics of the vertical profiles of components (maximum value of a variable, vertical position of this maximum, shape of vertical profile, width of peak with maximum) in the model with those characteristics in field data. This brings us to the conclusion that the model adequately describes the main physical, chemical and ecological processes in the lake and that we can use the model for checking various hypotheses on the functioning of the Lake Shira ecosystem in future investigations and for analyzing options for management of this economically important lake.

In more detail, the major innovations in the current model are in the introduction of the variables and the processes that describe the cycle of nitrogen and in the improvement of the description of phosphorus cycle (uptake, excretion etc.) in the lake. There were good reasons to focus on these aspects during the development of the new model. The characteristic features of a meromictic lake, in particular the permanent and strong temperature, density and chemical gradients, produce special conditions for the way biochemical elements cycle through the system. The detailed description of such features and their influences on different ecosystem processes is the important contribution of the model presented here to our understanding of the functioning of the reservoir.

The way the bacterial community is represented in the model was improved, too. Calculations with the earlier model showed that sulphur and sulphur green bacteria disappeared during the simulations (Degermendzhy et al. 2002) while new field observations showed that these species of bacteria are not dominant. As result, these species of bacteria were not present in the model described here. Finally, for another species (sulphur purple and sulphate-reducing bacteria), which are included in the model, some of the parameters were changed during the calibration, leading to a better correspondence between the calculations and the observations.
Another important new feature is the variables and processes governing the vertical distribution of amphipods Gammarus lacustris. The unique situation does occur that amphipods stay for a long time (at least 1 month) in the central deep part of the lake in the water column. Under these circumstances, we would like to know the influence of amphipods on other components of ecosystem. Here the model could be of help. We deliberately kept the description of amphipods simple and schematic because there are a lot of open questions about the dynamics of Gammarus in the pelagic part of Lake Shira. The model is now based on approximately all available data about feeding, vertical distribution and dynamic of Gammarus and development of this aspect of the model can only proceed after new field and laboratory data about Gammarus lacustris will have become available.

Interestingly, the results of our simulations show that the influence of a high biomass of Gammarus on other components (algae, detritus, and cyanobacteria) is not big as we had assumed before we did the calculations. The relatively small impact of Gammarus is due to the low value of growth and consumptions rates of amphipods we used in the model. Our results also lead us to believe that feeding is not the main reason for movement of amphopods to the deep layer of the water and that there are other reasons for this. These results of our calculations point to a more limited role for Gammarus in the functioning of the Lake Shira ecosystem and we are fairly confident about the validity of this new insight.

Important changes were made in the processes related to the dynamics of phytoplankton and zooplankton. But at the same time, this opened the way for even further development of biological model. There are good reasons to introduce into the model the variables and the processes for another phytoplankton species that dominate during different periods of summer season (for example, Microcystis sp.). The same applies for two species of Rotifera (Brachionus plicatilis and Hexarthra oxiura) which are important components of the pelagic zooplankton community of Shira Lake (Zadereev and Tolomeyev 2007). The current description of dominant crustaceans Arctodiaptomus salinus could be improved by taking account of the fact that the different instars of zooplankton occupy different habitats in the water column (Zadereev and Tolomeyev 2007). All these 
steps would allow describing more exactly not only the phyto- and zoo-plankton community itself, but as a consequence the season dynamic of oxygen, detritus and nutrients as well.

With regard to other ecosystem processes, the introduction of the impact of temperature was made where we considered it to be essential and where data were available. During summer season, the temperature change is considerable and there is a strong and sharp vertical temperature gradient. Of course, taking this vertical variation into account had a direct impact on the growth and respiration of phytoplankton and zooplankton at various depths.

The detailed description of the different physicalchemical factors (light, temperature, nutrient concentrations etc.) and processes (turbulent diffusion, oxidation etc.) makes it possible to better understand their roles in the dynamics of the ecosystem's states during summer season. For example, the our calculations show that the concentration of oxygen in the surface layers of water depends on the reaeration, which in turn depends on the strength of wind and temperature of surface water. Cyanobacteria form deep peak of biomass later in the season, compared with green algae because cyanobacteria have a higher optimal temperature for growth.

Sedimentation is one of the processes which defines the position of the peak of biomass of phytoplankton. The sharp gradient of temperature in the water column works as the barrier ("liquid bottom") on the settling of detritus and promotes the accumulation of detritus immediate below the thermocline. High value of turbulent diffusion in the high layers of water leads to uniform mixing of water and almost uniform concentrations of nutrients here and vice versa minimum value of turbulent diffusion near the bottom can not diffuse the high concentration of nutrients. But there are other ecological phenomena, which depend more on the biological processes than the physical-chemical ones. For example, the oxidation of hydrogen sulphide by purple sulphur bacteria is a more effective process than chemical oxidation. Another example is that the photosynthesis of phytoplankton creates a peak of oxygen concentration in the deep layers of water column.

Of course, very often it is not correct to strictly divide the biological and physical-chemical processes in the ecosystem. In this sense, combining the biological model with detailed hydrophysical model is the correct approach and even a necessity. This interaction is at the centre of a general simulation model as working tool for the analysis and prediction the state of the lake. This makes the model more complex and increases the potential and need for calibration of the model to the field data. However, our calculations show that the performance of a model not decreased due to the increased complexity and adjustability but instead performs better compared with the earlier model. For example, the earlier model did not represent the changes in the phytoplankton community mentioned earlier and while the earlier model already gave some answers to the questions about the underlying mechanisms which define the state of the ecosystem, the new model considerably improved our insight into the dynamics of the Lake Shira ecosystem.

\section{Conclusion}

A new vertical model of Lake Shira was developed and applied to simulate the profiles of the major components of ecosystem during summer season. The model describes the main biochemical processes in the aerobic and anaerobic zones of the lake as well as the hydrophysical processes-sedimentation and diffusion. The model is based on one-dimensional vertical differential equations and used the available meteorological and field observational data.

The good qualitative and quantitative agreement of the calculations with the field observations confirms our improved understanding of the functioning of the lake ecosystem. Nevertheless, a lot of the open questions which demand more precise definitions in the model remain. For example, we already know that in the future it will be necessary to change the model description of zooplankton. It might well be that we will have to use the individual-based approach instead of differential equations for this component of the ecosystem. For a more detailed description of the chemocline, it is needed to introduce in the model new bacterial variables and processes in future. One of the main tasks, which should take our attention permanently, is supplying the model with more detailed field data.

Nevertheless, the current state of the model opens the way for checking various hypotheses on the functioning of the Lake Shira ecosystem. The example of the using the model in investigation of sedimentation and succession of phytoplankton species is presented in this paper. We are optimistic 
about the use the model presented here for another meromictic lakes, and we are confident that the model will be helpful for the investigators of saline lake ecosystems in general.

Acknowledgments The work was supported by the grant NWO-RFBR 047.017.012 from The Netherlands Organization for Scientific Research and Russian Foundation for Basic Research and Integration project of SB RAS No. 95.

\section{Appendix 1: Process descriptions} for the biochemical components in the model

Green algae and cyanobacteria (suffix Spec $=$ Gren for green algae, = Blue for cyanobacteria)

$$
\begin{aligned}
& F=w D A s s \text { Spec } W(w P U p t \text { Spec }, w N U p t \text { Spec }) \\
& \text { - wDRespSpecW }(w P E x c r S p e c W, w N E x c r S p e c W) \\
& \text { - wDMortSpecW(wPMortSpecW,wNMortSpecW) } \\
& \text { - wDConsSpecZoo(wPConsSpecZoo, } \\
& \text { wNConsSpecZoo) } \\
& \text {-wDConsSpecGamm(wPConsSpecGamm, } \\
& \text { wNConsSpecGamm); } \\
& =\text { growth (uptake of nutrients) } \\
& \text { - respiration(excretion) - mortality } \\
& \text { - consumption by zooplankton } \\
& \text { - consumption by amphipod. }
\end{aligned}
$$

Zooplankton

$$
\begin{aligned}
& F=w D A s s Z o o(w P A s s Z o o, w N A s s Z o o) \\
& \text { - wDRespZoo(wPExcrZoo, wNExcrZoo) } \\
& \text { - wDMortZoo(wPMortZoo, wNMortZoo); } \\
& =\text { growth }- \text { respiration }(\text { excretion })-\text { mortality } \text {. }
\end{aligned}
$$

Amphipod (Gammarus lacustris)

$$
\begin{aligned}
\left.\begin{array}{rl}
F= & w D A s s G a m m(w P A s s G a m m, w N A s s G a m m
\end{array}\right) \\
\\
\quad-w D M o r t G a m m(w P M o r t G a m m, w N M o r t G a m m) ; \\
=\text { growth }- \text { mortality. }
\end{aligned}
$$

Purple sulphur bacteria

$F=w D A s s S P B a c t W-w D M o r t S P B a c t W ;$

$=$ growth - mortality.
Sulphate-reducing bacteria

$F=w D A s s S R B a c t W-w D M o r t S R B a c t W ;$

$=$ growth - mortality.

Detritus

$$
\begin{aligned}
& F=w D M o r t P h y t W \\
& \text { (wPMortPhytDetW,wNMortPhytDetW) } \\
& +w D M o r t S P B a c t W \\
& \text { (wPMortSPBactW, wNMortSPBactW) } \\
& +w D M o r t S R B a c t W \\
& \text { (wPMortSRBactW, wNMortSRBactW) } \\
& +w \text { DMortZoo(wPMortZooDet, wNMortZooDet) } \\
& +w D E g e s Z o o(w P E g e s Z o o D e t, w N E g e s Z o o D e t) \\
& +w D E g e s S R B a c t W \\
& \text { (wPEgesSRBactWDet, wNEgesSRBactWDet) } \\
& \text { - wDMinDetW(wPMinDetW, wNMinDetW) } \\
& \text { - wDConsDetSRBactW } \\
& \text { (wPConsDetSRBactW, wNConsDetSRBactW) } \\
& \text { - wDConsDetZoo } \\
& \text { (wPConsDetZoo, wNConsDetZoo) } \\
& + \text { wDMortGamm } \\
& \text { (wPMortGammDet, wNMortGammDet) } \\
& + \text { wDEgesGamm } \\
& \text { (wPEgesGammDet, wNEgesGammDet) } \\
& \text { - wDConsDetGamm } \\
& \text { (wPConsDetGamm,wNConsDetGamm); } \\
& =\text { mortality of phytoplankton } \\
& + \text { mortality of purple sulphur bacteria } \\
& + \text { mortality of sulphate - reducing bacteria } \\
& + \text { mortality of zooplankton } \\
& + \text { egestion of zooplankton } \\
& + \text { egestion of sulphate-reducing bacteria } \\
& \text { - mineralization } \\
& \text { - consumption by sulphate - reducing bacteria } \\
& \text { - consumption by zooplankton } \\
& + \text { mortality of amphipod } \\
& + \text { egestion of amphipod } \\
& \text { - consumption by amphipod. }
\end{aligned}
$$


Phosphorus $\mathrm{PO}_{4}$

$$
\begin{aligned}
F= & w P E x c r P h y t W+w P M o r t P h y t P O 4 W \\
& +w P M i n D e t W+w P E g e s S R B a c t W P O 4 \\
& +w P E x c r Z o o+w P E g e s Z o o P O 4 \\
& +w P M o r t Z o o P O 4-w P U p t P h y t \\
& +w P E g e s G a m m P O 4+w P M o r t G a m m P O 4 \\
= & \text { excretion of phytoplankton } \\
& + \text { mortality of phytoplankton } \\
& + \text { mineralization of detritus } \\
& + \text { egestion of sulphate }- \text { reducing bacteria } \\
& + \text { excretion of zooplankton } \\
& + \text { egestion of zooplankton } \\
& + \text { mortality of zooplankton } \\
& - \text { uptake by phytoplankton } \\
& + \text { egestion of amphipod } \\
& + \text { mortality of amphipod. }
\end{aligned}
$$

Ammonium $\mathrm{NH}_{4}$

$$
\begin{aligned}
F= & w N E x c r P h y t W+w N M o r t P h y t N H 4 W \\
& +w N M i n D e t W+w N E g e s S R B a c t W N H 4 \\
& +w N E x c r Z o o+w N E g e s Z o o N H 4 \\
& +w N M o r t Z o o N H 4-w N N i t r W \\
& -w N U p t N H 4 P h y t+w N E g e s G a m m N H 4 \\
& +w N M o r t G a m m N H 4 \\
= & \text { excretion of phytoplankton } \\
& + \text { egestion of sulphate }- \text { reducing bacteria } \\
& + \text { excretion of zooplankton } \\
& + \text { egestion of zooplankton } \\
& + \text { mortality of zooplankton }- \text { nitrification } \\
& - \text { uptake by phytoplankton } \\
& + \text { egestion of amphipod } \\
& + \text { mortality of amphipod. }
\end{aligned}
$$

Nitrate $\mathrm{NO}_{3}$

$$
\begin{aligned}
F & =w N N i t r W-w N D e n i t W-w N U p t N O 3 P h y t ; \\
= & \text { nitrification }- \text { denitrification } \\
& \quad \text { uptake by phytoplankton. }
\end{aligned}
$$

Oxygen $\mathrm{O}_{2}$

$$
\begin{aligned}
F= & w O 2 \operatorname{Pr} \text { odPhyt }+ \text { wO2UptNO3Phyt } \\
& -w O 2 \operatorname{Re} s p P h y t-w O 2 M i n D e t W-w O 2 N i t r W \\
& -2^{*} w H 2 S O x O 2-w O 2 O x H 2 S S P B a c t
\end{aligned}
$$

$=$ production by phytoplankton

+ uptake nitrate by phytoplankton

- respiration of phytoplankton

- mineralization of detritus - nitrification

- chemical oxidation of hydrogen sulphide

- oxidation of hydrogen sulphide by purple sulphur bacteria.

Hydrogen sulphide $\mathrm{H}_{2} \mathrm{~S}$

$$
\begin{aligned}
F= & w H 2 S F \text { ormSRBact }-w H 2 S O x O 2 \\
& -w H 2 S O x S P B a c t \\
= & \text { sulphate reduction } \\
& - \text { chemical oxidation of hydrogen sulphide } \\
- & \text { oxidation of hydrogen sulphide by purple sulphur } \\
& \text { bacteria. }
\end{aligned}
$$

\section{Appendix 2: Auxiliary equations used in the model}

Green algae and cyanobacteria

uFunTmSpec is temperature function of Spec, where suffix Spec $=$ Gren for green algae, $=$ Blue for cyanobacteria

$$
u \text { FunTmSpec }=\exp \left[-\frac{(s T m W[i]-c \text { TmOptSpec })^{2}}{c \text { SigTmSpec }}{ }^{2}\right] .
$$


aLLimSpec is light function of growth rate of Spec

$$
\begin{aligned}
& \frac{s L i g h t 1[i]}{c L 1 B 1 \text { Spec }} \quad \text { if } \quad s L i g h t 1[i] \leq c L 1 B 1 \text { Spec } \\
& \text { aLLimSpec }=\begin{array}{ccc}
1 & \text { if } \quad c L 1 B 1 \text { Spec }<\text { sLight } 1[i] \leq c L 1 B 2 \text { Spec } \\
\frac{(c L 1 B 3 \text { Spec }- \text { sLight } 1[i])}{(c L 1 B 3 \text { Spec }-c L 1 B 2 \text { Spec })} & \text { if } & c L 1 B 2 \text { Spec }<\text { sLight } 1[i] \leq c L 1 B 3 \text { Spec }
\end{array} \\
& 0 \quad \text { if } \operatorname{sLight} 1[i]>c L 1 B 3 \text { Spec }
\end{aligned}
$$

aNutLimSpec is nutrient limitation function of Spec

aNutLimSpec $=\min ($ aPLimSpec, aNLimSpec $)$,

aPLimSpec is dependence of growth rate from internal $\mathrm{P}$ concentration

$$
\begin{aligned}
\text { aPLimSpec }= & \left(1-\frac{c P D \text { SpecMin }}{r P D \text { Spec }}\right) \\
& \cdot \frac{\text { cPDSpecMax }}{\text { cPDSpecMax }- \text { cPDSpecMin }} .
\end{aligned}
$$

aNLimSpec is dependence of growth rate from internal $\mathrm{N}$ concentration

$$
\begin{aligned}
\text { aNLimSpec }= & \left(1-\frac{c N D S p e c M i n}{r N D S p e c}\right) \\
& \cdot \frac{c N D S p e c M a x}{c N D S p e c M a x-c N D S p e c M i n} .
\end{aligned}
$$

wPUptSpec is P uptake of Spec

$w P U p t$ Spec $=a V P U p t$ Spec $\cdot s D$ Spec $W[i]$.

aVPUptSpec is $\mathrm{P}$ uptake rate of algae

aVPUptSpec $=$ aVPUptMaxCorSpec

$$
\cdot \frac{s P O 4 W[i]}{s P O 4 W[i]+h P U p t \text { Spec }} \text {. }
$$

aVPUptMaxCorSpec is maximum $\mathrm{P}$ uptake rate of Spec, corrected for $P / D W$ ratio

$$
\begin{aligned}
\text { aVPUptMaxCorSpec }= & c \text { VPUptMaxSpec } \\
& \cdot \text { uFunTmSpec } \\
& \cdot \frac{c P D S p e c M a x-r P D S p e c}{c P D S p e c M a x-c P D S p e c M i n} .
\end{aligned}
$$

$w N U p t$ Spec is $\mathrm{N}$ uptake of Spec

$w N U p t$ Spec $=a V N U p t$ Spec $\cdot s D$ Spec $W[i]$.

$a V N U p t$ Spec is $\mathrm{N}$ uptake rate of algae $a V N U p t S p e c=a V N U p t M a x C o r S p e c$

$$
\cdot \frac{o N D i s s W[i]}{\text { oNDiss } W[i]+h N U p t \text { Spec }} \text {. }
$$

aVNUptMaxCorSpec is maximum $\mathrm{N}$ uptake rate of Spec, corrected for $N / D W$ ratio

$$
\begin{aligned}
\text { aVNUptMaxCorSpec }= & c \text { VNUptMaxSpec } \\
& \cdot u \text { FunTmSpec } \\
& \cdot \frac{c N D S p e c M a x-r N D S p e c}{c N D S p e c M a x-c N D S p e c M i n} .
\end{aligned}
$$

wPExcrSpec $W$ is P excretion of Spec

$$
\begin{aligned}
& w P \text { ExcrSpec } W=\frac{r P D \text { Spec } W}{c P D S p e c M i n+r P D S p e c W} \\
& \text { - rPDSpecW } \cdot w D \operatorname{RespSpec} W \text {. }
\end{aligned}
$$

wNExcrSpecW is $\mathrm{N}$ excretion of Spec

$$
\begin{aligned}
w N E x c r \text { Spec } W= & \frac{r N D S p e c W}{c N D \text { SpecMin }+r N D S p e c W} \\
& \cdot r N D \text { Spec } W \cdot w D \operatorname{RespSpec} W .
\end{aligned}
$$

wPMortSpecW is mortality of Spec

$w P M o r t S p e c W=k M o r t S p e c W \cdot \operatorname{sPpec} W[i]$,

wNMortSpec $W$ is mortality of Spec

wNMortSpec $W=k M$ ortSpec $W \cdot \operatorname{sNSpec} W[i]$

Zooplankton

uFunTmZoo is temperature function of zooplankton

$u$ FunTmZoo $=\exp \left[-\frac{(s \operatorname{Tm} W[i]-c \operatorname{TmOptZoo})^{2}}{c \operatorname{SigTmZoo}{ }^{2}}\right]$.

aAlg LimZoo is food limitation function

if $\quad s D G r e n W[i]+s D B l u e W[i]+s D \operatorname{Det} W[i]$

$<t D A \lg Z o o \quad$ aA $\lg$ LimZoo $=0$, 


$$
\begin{aligned}
& \text { if } \quad s D \text { Gren } W[i]+s D \text { BlueW }[i]+s D D e t W[i]>t D A \lg \text { Zoo } \\
& a A \lg \text { LimZoo }=\frac{s D G r e n W[i]+s D B l \text { ue } W[i]+s D D e t W[i]-t D A \lg \text { Zoo }}{s D \text { Gren } W[i]+s D B l u e W[i]+s D D e t W[i]-t D A \lg Z o o+h D A \lg \text { Zoo }} .
\end{aligned}
$$

$w P A s s Z o o$ is assimilation of zooplankton

$w P A s s Z o o=$ afPAssZoo $\cdot w$ PConsZoo.

afPAssZoo is $\mathrm{P}$ assimilation efficiency of zooplankton

afPAssZoo $=$ MIN $\left(1, \frac{c \text { PDZooRe } f}{\text { rPDFoodZoo }} \cdot\right.$ fDAssZoo $)$.

rPDFoodZoo is $P / D W$ ratio of zooplankton food

rPDFoodZoo $=$ oPFoodZoo $/$ oDFoodZoo.

oDFoodZoo is zooplankton food

$$
\begin{aligned}
\text { oDFoodZoo }= & c \operatorname{Pr} \text { efGren } \cdot \text { sDGren } W[i] \\
& +c \operatorname{Pr} \text { efBlue } \cdot \text { sDBlueW }[i] \\
& +c \operatorname{Pr} \text { efDet } \cdot \text { sDDet } W[i] .
\end{aligned}
$$

$c$ Pr efSpec is selection factor for Spec, Spec $=G$ ren for green algae, = Blue for cyanobacteria, $=$ Det for detritus

$c \operatorname{Pr}$ efSpec $=\frac{s D \text { Spec } W[i]}{s D \text { Gren } W[i]+s D B l u e W[i]+s D \operatorname{Det} W[i]}$.

oPFoodZoo is zooplankton food

oPFoodZoo $=c \operatorname{Pr}$ efGren $\cdot s$ PGren $W[i]+c \operatorname{Pr}$ efBlue $\cdot s P B l u e W[i]+c \operatorname{Pr} e f D e t \cdot s P \operatorname{Det} W[i]$.

wPConsZoo is total $\mathrm{P}$ consumption

$$
w \text { PConsZoo }=w \text { PConsGrenZoo }+w \text { PConsBlueZoo }
$$$$
+w P C o n s D e t Z o o \text {. }
$$

wPConsSpecZoo is Spec P consumption by zooplankton, Spec $=$ Gren for green algae, $=$ Blue for cyanobacteria, $=$ Det for detritus

$w P C o n s$ SpecZoo $=r P D$ Spec $W \cdot w D$ ConsSpecZoo.

wDConsZoo is consumption of zooplankton

$w$ DConsZoo $=w D A s s Z o o / f D A s s Z o o$.

$w N A s s Z o o$ is assimilation of zooplankton

$w N A s s Z o o=$ afNAssZoo $\cdot w$ NConsZoo.
afNAssZoo is $\mathrm{N}$ assimilation efficiency of zooplankton

afNAssZoo $=$ MIN $\left(1, \frac{c N D Z o o \text { Ref }}{r N D F o o d Z o o} \cdot f D A s s Z o o\right)$.

rNDFoodZoo is N/DW ratio of zooplankton food $r N D F o o d Z o o=o N F o o d Z o o / o D F o o d Z o o$.

oNFoodZoo is zooplankton food

$$
\begin{aligned}
\text { oNFoodZoo }= & c \operatorname{Pr} \text { efGren } \cdot \text { sNGren } W[i] \\
& +c \operatorname{Pr} \text { efBlue } \cdot \text { sNBlue } W[i] \\
& +c \operatorname{Pr} \text { efDet } \cdot \text { sNDet } W[i] .
\end{aligned}
$$

wNConsZoo is total $\mathrm{N}$ consumption

$$
w \text { NConsZoo }=w \text { NConsGrenZoo }+w \text { NConsBlueZoo }
$$$$
+w \text { NConsDetZoo. }
$$

wNConsSpecZoo is Spec N consumption by zooplankton, Spec $=$ Gren for green algae, $=$ Blue for cyanobacteria, $=$ Det for detritus

$w N C o n s$ SpecZoo $=r N D$ Spec $W \cdot w D$ ConsSpecZoo.

aCorDRe spZoo is correction factor of zooplankton respiration for $\mathrm{P}$ and $\mathrm{N}$ content

aCorDRespZoo

$=$ MAX (cPDZooRef/rPDZoo;cNDZooRef/rNDZoo $)$.

wPMortZoo is zooplankton mortality

$w$ PMortZoo $=r$ PDZoo $\cdot w$ DMortZoo.

$w N M o r t Z o o$ is zooplankton mortality

$w$ NMortZoo $=r N D Z o o \cdot w D M o r t Z o o$.

Amphipods (Gammarus lacustris)

uFunTmGamm is temperature function of amphipods

uFunTmGamm $=\exp \left[-\frac{(s \operatorname{TmW}[i]-c \text { TmOptGamm })^{2}}{c \operatorname{SigTmGamm}{ }^{2}}\right]$. 
wPAssGamm is assimilation of amphipods

$w P A s s G a m m=$ afPAssGamm $\cdot w P$ ConsGamm.

afPAssGamm is $\mathrm{P}$ assimilation efficiency of amphipods

afPAssGamm

$$
=\operatorname{MIN}\left(1, \frac{c \text { PDGamm }}{\text { rPDFoodGamm }} \cdot \text { fDAssGamm }\right) \text {. }
$$

rPDFoodGamm is $P / D W$ ratio of amphipods food rPDFoodGamm = oPFoodGamm/oDFoodGamm.

oDFoodGamm is amphipods food

$o$ DFoodGamm $=o$ DFoodZoo.

oPFoodGamm is amphipods food

oPFoodGamm $=$ oPFoodZoo.

wPConsGamm is total $\mathrm{P}$ consumption by amphipods

$$
\begin{aligned}
w \text { PConsGamm }= & w \text { PConsGrenGamm } \\
& + \text { wPConsBlueGamm } \\
& + \text { wPConsDetGamm. }
\end{aligned}
$$

wPConsSpecGamm is Spec $\mathrm{P}$ consumption by amphipods, Spec $=$ Gren for green algae, $=$ Blue for cyanobacteria, $=$ Det for detritus

$w P$ ConsSpecGamm $=r P D$ Spec $W$

$$
\text { - wDConsSpecGamm. }
$$

wDConsGamm is consumption of amphipods

$w$ DConsGamm $=w D A s s G a m m / f D A s s G a m m$.

wNAssGamm is assimilation of amphipods

wNAssGamm = afNAssGamm $\cdot$ wNConsGamm.

aFNAssGamm is $\mathrm{N}$ assimilation efficiency of amphipods

afNAssGamm

$$
=\operatorname{MIN}\left(1, \frac{c N D G a m m}{\text { rNDFoodGamm }} \cdot \text { fDAssGamm }\right) .
$$

rNDFoodGamm is N/DW ratio of amphipods food rNDFoodGamm = oNFoodGamm/oDFoodGamm.

oNFoodGamm is amphipods food oNFoodGamm = oNFoodZoo.
wNConsGamm is total $\mathrm{N}$ consumption by amphipods

$$
\begin{aligned}
\text { wNConsGamm }= & \text { wNConsGrenGamm } \\
& + \text { wNConsBlueGamm } \\
& + \text { wNConsDetGamm. }
\end{aligned}
$$

wNConsSpecGamm is Spec N consumption by amphipods, Spec $=$ Gren for green algae, $=$ Blue for cyanobacteria, $=$ Det for detritus

$w N$ ConsSpecGamm $=r N D$ Spec $W$

$$
\text { -wDConsSpecGamm. }
$$

wPMortGamm is amphipods mortality $w$ PMortGamm $=c$ PDGamm $\cdot w$ DMortGamm.

wNMortGamm is amphipods mortality $w N M o r t G a m m=c N D G a m m \cdot w D M o r t G a m m$. Purple sulphur bacteria $a M u S P B a c t W$ is specific growth rate

$$
\text { if } \quad s \text { Light } 2[i]<c \text { Light } 2 \text { Bound } 1
$$$$
a M u S P B a c t=k M u M a x S P B a c t 1
$$

$$
\begin{aligned}
& \cdot \frac{s O 2 W[i]}{h O 2 S P B a c t O 2+s O 2 W[i]} \\
& \cdot \frac{s H 2 S W[i]}{h H 2 S S P B a c t O 2+s H 2 S W[i]},
\end{aligned}
$$

if $\quad$ LLight 2 Bound $2>\operatorname{sLight} 2[i]>c$ Light 2 Bound 1

$$
\begin{aligned}
a M u S P B a c t= & k M u M a x S P B a c t 2 \cdot \frac{s L i g h t 2[i]}{c L i g h t 2 \text { Bound } 2} \\
& \cdot \frac{1-s O 2 W[i]}{i O 2 S P B a c t} \\
& \cdot \frac{s H 2 S W[i]}{h H 2 S S P B a c t L i g h t+s H 2 S W[i]},
\end{aligned}
$$

if $\quad s L i g h t 2[i]>c$ Light 2 Bound 2 $a M u S P B a c t=k M u M a x S P B a c t 2$

$$
\begin{aligned}
& \cdot \frac{1-s O 2 W[i]}{i O 2 S P B a c t} \\
& \cdot \frac{s H 2 S W[i]}{h H 2 S S P B a c t \text { Light }+s H 2 S W[i]} \text {. }
\end{aligned}
$$

$k M o r t S P B a c t W$ is specific mortality rate if $\quad s$ Light $2[i]<$ LLight 2 Bound 1 kMortSPBactW $=$ kMortSPBactO2, 
if $\quad$ sLight $2[i] \geq c$ Light 2 Bound 1

$k M o r t S P B a c t W=k M o r t S P B a c t$ Light .

Sulphate-reducing bacteria

aMuSRBactW is specific growth rate

$$
\begin{aligned}
\text { aMuSRBact } W= & k \text { MuMaxSRBact } \cdot \frac{1-s O 2 W[i]}{i O 2 S R B a c t} \\
& \cdot \frac{1-s H 2 S W[i]}{i H 2 S S R B a c t} \\
& \cdot \frac{\text { sDDetW }[i]}{\text { sDDetW }[i]+\text { hOMSRBact }} .
\end{aligned}
$$

Detritus

wPMortPhytDetW is detrital $\mathrm{P}$ flux from died phytoplankton

$$
\begin{aligned}
& w \text { PMortPhytDet } W \\
& =(w P M o r t B l u e W+w P M o r t G r e n W) \\
& \quad-w P M o r t P h y t P O 4 W .
\end{aligned}
$$

wNMortPhytDetW is detrital $\mathrm{N}$ flux from died phytoplankton

$$
\begin{aligned}
& w N M o r t P h y t D e t W \\
&=(w N M o r t B l u e W+w N M o r t G r e n W) \\
&-w N M o r t P h y t N H 4 W .
\end{aligned}
$$

wPMortSPBactW is $\mathrm{P}$ flux from died purple sulphur bacteria

$$
\begin{aligned}
w P M o r t S P B a c t W= & w D M o r t S P B a c t W \\
& \cdot c P D S P \text { PrpBact } W .
\end{aligned}
$$

$w N M o r t S P B a c t W$ is $\mathrm{N}$ flux from died purple sulphur bacteria

$$
\begin{aligned}
w N M o r t S P B a c t W= & w D M o r t S P B a c t W \\
& \cdot c N D S P u r p B a c t W .
\end{aligned}
$$

wPMortSRBactW is $\mathrm{P}$ flux from died sulphatereducing bacteria

$$
\begin{aligned}
w P M o r t S R B a c t W= & w D M o r t S R B a c t W \\
& \cdot c P D S R B a c t W .
\end{aligned}
$$

$w N M o r t S R B a c t W$ is $\mathrm{N}$ flux from died sulphatereducing bacteria

$w N M o r t S R B a c t W=w D M o r t S R B a c t W$

$$
\text { - cNDSRBactW. }
$$

wPMortZooDet is detrital $\mathrm{P}$ flux from died zooplankton

$w$ PMortZooDet $=w$ PMortZoo $-w P$ MortZooPO4.

wNMortZooDet is detrital $\mathrm{N}$ flux from died zooplankton

$w N M o r t Z o o D e t=w N M o r t Z o o-w N M o r t Z o o N H 4$.

wPEgesZooDet is detrital $\mathrm{P}$ egestion of zooplankton

$w P$ EgesZooDet $=w P$ EgesZoo $-w P$ EgesZooPO4.

$w P E g e s Z o o$ is $\mathrm{P}$ egestion of zooplankton

$w P$ EgesZoo $=w P C o n s Z o o-w P A s s Z o o$.

wNEgesZooDet is detrital $\mathrm{N}$ egestion of zooplankton

$w N E g e s Z o o D e t=w N E g e s Z o o-w N E g e s Z o o N H 4$.

wNEgesZoo is $\mathrm{N}$ egestion of zooplankton

$w N E g e s Z o o=w N C o n s Z o o-w N A s s Z o o$.

wPEgesSRBactWDet is detrital $\mathrm{P}$ egestion of sulphate-reducing bacteria

$w P E g e s S R B a c t W D e t=w P E g e s S R B a c t W$ - wPEgesSRBactWPO4.

wPEgesSRBactW is $\mathrm{P}$ egestion of sulphate-reducing bacteria

$w P E g e s S R B a c t W=w P C o n s D e t S R B a c t W$ - wPAssSRBactW.

$w P C o n s$ DetSRBact $W$ is consumption of detritus by sulphate-reducing bacteria

$$
\begin{aligned}
w P C o n s D e t S R B a c t W= & w \text { DConsDetSRBact } W \\
& \cdot r P D D e t W .
\end{aligned}
$$

wPAssSRBactW is assimilation of sulphate-reducing bacteria

$$
\begin{aligned}
w P A s s R B \text { Bact } W= & w P \text { ConsDetSRBact } W \\
& \cdot y \text { OMSRBact } W ;
\end{aligned}
$$

wNEgesSRBactWDet is detrital $\mathrm{N}$ egestion of sulphate-reducing bacteria

$w N E g e s S R B a c t W D e t=w N E g e s S R B a c t W$

$$
\text { - wNEgesSRBactWNH4. }
$$


wNEgesSRBact $W$ is $\mathrm{N}$ egestion by sulphate-reducing bacteria

$$
\begin{aligned}
w N E g e s S R B a c t W= & w N C o n s D e t S R B a c t W \\
& -w N A s s \text { SBact } W .
\end{aligned}
$$

$w N C o n s$ DetSRBactW is consumption of detritus by sulphate-reducing bacteria

$$
\begin{aligned}
w N C \text { ConsDetSRBact } W= & w \text { DConsDetSRBact } W \\
& \cdot r N D D e t W .
\end{aligned}
$$

wNAssSRBactW is assimilation of sulphate-reducing bacteria

$$
\begin{aligned}
w N A s s S R B a c t W= & w N C \text { ConsDetSRBact } W \\
& \cdot y \text { OMSRBact } W .
\end{aligned}
$$

wPMortGammDet is detrital $\mathrm{P}$ flux from died amphipods

$$
\begin{aligned}
w \text { PMortGammDet }= & \text { wPMortGamm } \\
& - \text { wPMortGammPO4. }
\end{aligned}
$$

wNMortGammDet is detrital $\mathrm{N}$ flux from died amphipods

$$
\begin{aligned}
w \text { NMortGammDet }= & \text { wNMortGamm } \\
& - \text { wNMortGammNH4. }
\end{aligned}
$$

wPEgesGammDet is detrital $\mathrm{P}$ egestion of amphipods

$$
\begin{aligned}
\text { wPEgesGammDet }= & \text { wPEgesGamm } \\
& - \text { wPEgesGammPO4. }
\end{aligned}
$$

wPEgesGamm is $\mathrm{P}$ egestion of amphipods $w P$ EgesGamm $=w$ PConsGamm $-w$ PAssGamm.

wNEgesGammDet is detrital $\mathrm{N}$ egestion of amphipods

$$
\begin{aligned}
w N E g e s G a m m D e t= & w N E g e s \text { Gamm } \\
& -w N E g e s G a m m N H 4 .
\end{aligned}
$$

wNEgesGamm is $\mathrm{N}$ egestion of amphipods $w N E g e s G a m m=w N C o n s G a m m-w N A s s$ Gamm.

uFunTmMinW is temperature correlation of mineralization

uFunTmMin $W=\theta_{\min }^{s T m W[i]-T^{0}}$.

Nitrogen (Ammonium $\mathrm{NH}_{4}$ and Nitrate $\mathrm{NO}_{3}$ )

oNDiss $W[i]$ is nitrogen concentration in $i$ depth $o N D i s s W[i]=s N O 3 W[i]+s N H 4 W[i]$.
uFunTmNitr is temperature correction of nitrification

uFunTmNitr $=\theta_{\text {nitr }}^{s T m W[i]-T^{0}}$.

aCorO2NitrW is correction of nitrification at low oxygen concentration

aCorO2NitrW

$$
=\frac{s O 2 W[i] \cdot s O 2 W[i]}{s O 2 W[i] \cdot s O 2 W[i]+h O 2 N i t r \cdot h O 2 N i t r} .
$$

aCorO2BOD is correction of $\mathrm{O}_{2}$ demand in water at low oxygen concentration

$a C o r O 2 B O D=\frac{s O 2 W[i]}{s O 2 W[i]+h O 2 B O D}$.

wNUptNH4Spec is ammonium uptake by Spec, Spec $=$ Gren for green algae, $=$ Blue for cyanobacteria

$w N U p t N H 4 S p e c=a f N H 4 U p t S p e c \cdot w N U p t S p e c$.

afNH4UptSpec is fraction ammonium uptake by Spec

afNH4UptSpec

$$
\begin{aligned}
& =\frac{s N H 4 W[i] \cdot s N O 3 W[i]}{(h N U p t \text { Spec }+s N H 4 W[i]) \cdot(h N U p t \text { Spec }+s N O 3 W[i])} \\
& +\frac{s N H 4 W[i] \cdot h N U p t \text { Spec }}{(s N H 4 W[i]+s N O 3 W[i]) \cdot(h N U p t S p e c+s N O 3 W[i])} .
\end{aligned}
$$

$w N U p t N O 3 S p e c$ is nitrate uptake by Spec, Spec $=$ Gren for green algae, = Blue for cyanobacteria

$w N U p t N O 3 S p e c=w N U p t S p e c-w N U p t N H 4 S p e c$.

Hydrogen sulphide $\mathrm{H}_{2} \mathrm{~S}$

$y H 2 S S P B a c t$ is yield factor $\mathrm{H}_{2} \mathrm{~S}$ for sulphur purple bacteria

$$
\begin{aligned}
& \text { if } \quad \text { sLight } 2[i]<c \text { Light } 2 \text { Bound } 1 \\
& y H 2 S S P B a c t=y H 2 S S P B a c t O 2, \\
& \text { if } \quad \text { sLight } 2[i]>c \text { Light } 2 \text { Bound } 1 \\
& y H 2 S S P B a c t=y H 2 S S P B a c t \text { Light } . \\
& \text { Oxygen } \mathrm{O}_{2}
\end{aligned}
$$

fO2AssSPBact is oxidation constant for purple bacteria 


\author{
if $\quad s L i g h t 2[i]<$ LLight 2 Bound 1 \\ fO2AssSPBact $=1 /$ yO2SPBactO2, \\ if $\quad s L i g h t 2[i]>$ cLight 2 Bound 1 \\ fO2AssPBact $=0$.
}

\section{References}

Antonopoulos VZ, Gianniou SK (2003) Simulation of water temperature and dissolved oxygen distribution in Lake Vegoritis, Greece. Ecol Modell 160:39-53

Belolipetskii VM, Genova SN (1998) Investigation of hydrothermal and ice regimes in hydropower station bays. Int $\mathrm{J}$ Comput Fluid Dyn 10:151-158

Belolipetsky PV, Belolipetskii VM, Genova SN (2010) Numerical modelling of vertical stratification of Shira Lake in summer. Aquat Ecol (in press)

Bonnet MP, Wessen K (2001) ELMO, a 3-D water quality model for nutrients and chlorophyll: first application on a lacustrine ecosystem. Ecol Modell 141:19-33

Bruce LC, Hamilton D, Imberger J, Gal G, Gophen M, Zohary T, Hambright KD (2006) A numerical simulation of the role of zooplankton in $\mathrm{C}, \mathrm{N}$ and $\mathrm{P}$ cycling in Lake Kinneret, Israel. Ecol Modell 193(3-4):412-436

Burger DF, Hamilton DP, Pilditch CA (2008) Modelling the relative importance of internal and external nutrient loads on water column nutrient concentrations and phytoplankton biomass in a shallow polymictic lake. Ecol Modell 211(3-4):411-423

De Wit R, van den Ende FP, van Gemerden H (1995) Mathematical simulation of the interactions among cyanobacteria, purple sulfur bacteria and chemotrophic sulfur bacteria in microbial mat communities. FEMS Microbiol Ecol 17:117-136

Degermendzhy AG, Belolipetsky VM, Zotina TA, Gulati RD (2002) Formation of the vertical heterogeneity in the Lake Shira ecosystem: the biological mechanisms and mathematical model. Aquat Ecol 36(2):271-297

Gaevsky NA, Zotina TA, Gorbaneva TB (2002) Vertical structure and photosynthetic activity of Shira Lake phytoplankton. Aquat Ecol 36(2):165-178

Gal G, Imberger J, Zohary T, Antenucci J, Anis A, Rosenberg $\mathrm{T}$ (2003) Simulating the thermal dynamics of Lake Kinneret. Ecol Modell 162:69-86

Gutelmacher BL (1986) Metabolism of plankton as a single whole: trophometabolic interaction between zoo- and phytoplankton. Nauka, Leningrad

Janse JH (2005) Model studies on the eutrophication of shallow lakes and ditches. Thesis Wageningen University

Jorgensen SE, Friis HB, Henriken J, Mejer HF (eds) (1978) Handbook of environmental data and ecological parameters. ISEM Vaelse Denmark

Kalacheva GS, Gubanov VG, Gribovskaya IV, Gladchenko IA, Zinenko GK, Savitsky SV (2002) Chemical analysis of Lake Shira water (1997-2000). Aquat Ecol 36(2):123-141

Khmeleva NN (1988) Zakonomernosti razmnojeniya rakoobraznix. Nauka i Tehnika, Moscow (in Russian)
Kopylov AI, Kosolapov DB, Degermendzhy NN, Zotina TA, Romanenko AV (2002a) Phytoplankton, bacterial production and protozoan bacterivory in stratified brackishwater Lake Shira (Khakasia, Siberia). Aquat Ecol 36(2):205-218

Kopylov AI, Kosolapov DB, Romanenko AV, Degermendzhy AG (2002b) Structure of planktonic microbial food web in a brackish stratified Siberian lake. Aquat Ecol 36(2):179204

Kuznetsov CI (1970) Microflora of lakes and its geochemical activity. Nauka, Leningrad

Lunina ON, Bryantseva IA, Akimov VN, Rusanov II, Barinova ES, Lysenko AM, Rogozin DYu, Pimenov NV (2007) Anoxigenic phototrophic bacteria community of Lake Shira (Khakassia). Microbiology (Translated from Mikrobiologiya) 76(4):469

Morris MD (1991) Factorial sampling plans for preliminary computational experiments. Technometrics 33(2):161174

Omlin M, Reichert P, Forster R (2001) Biogeochemical model of Lake Zurich: model equations and results. Ecol Modell 141:77-103

Pfenning N (1989) Ecology of phototrophic purple and green sulphur bacteria. In: Pfenning N (ed) Autotrophical bacteria. Springer, Berlin, pp 97-116

Pimenov NV, Rusanov II, Karnachuk OV, Rogozin DYu, Bryantseva IA, Lunina ON, Yusupov SK, Parnachev VP, Ivanov MV (2003) Microbial processes of the carbon and sulfur cycles in Lake Shira (Khakasia). Microbiology (Translated from Mikrobiologiya) 72(2):221-229

Prokopkin IG, Gubanov VG, Gladyshev MI (2006) Modelling the effect of planktivorous fish removal in a reservoir on the biomass of cyanobacteria. Ecol Modell 190(3-4):419431

Reichert P (1994) AQUASIM-a tool for simulation and data analysis of aquatic systems. Water Sci Tech 30:21-30

Rogozin DY, Zykov VV, Chernetsky MY, Degermendzhy AG, Gulati RD (2009) Effect of winter conditions on distributions of anoxic phototrophic bacteria in two meromictic lakes in Siberia, Russia. Aquat Ecol 43(3):661-672

Romero JR, Antenucci JP, Imberger J (2004) One- and threedimensional biogeochemical simulations of two differing reservoirs. Ecol Modell 174(1-2):143-160

Rukhovets LA, Astrakhantsev GP, Menshutkin VV, Minina TR, Petrova NA, Poloskov VN (2003) Development of Lake Ladoga ecosystem models: modeling of the phytoplankton succession in the eutrophication process. Ecol Modell 165:49-77

Saltelli A, Chan K, Scott EM (eds) (2000) Sensitivity analysis. Wiley

Temerova TA, Tolomeyev AP, Degermendzhy AG (2002) Growth of dominant zooplankton species feeding on plankton micriflora in Lake Shira. Aquat Ecol 36(2):235243

Tolomeyev AP, Zadereev ES, Degermendzhy AG (2006) Fine stratified distribution of Gammarus lacustris sars (Crustacea: Amphipoda) in the pelagic zone of the meromictic Lake Shira (Khakassia, Russia). Dokl Biochem Biophys 411(1):346-348

Trolle D, Jorgensen TB, Jeppesen E (2008) Predicting the effects of reduced external nitrogen loading on the 
nitrogen dynamics and ecological state of deep Lake Ravn, Denmark, using the DYRESM-CAEDYM model. Limnologica - Ecol Manag Inland Waters 38(3-4):220232

Truper HG (1989) Physiology and biochemistry of phototrophic bacteria. In: Pfenning N (ed) Autotrophical bacteria. Springer, Berlin, pp 267-281

Zadereev YeS, Tolomeyev AP (2007) The vertical distribution of zooplankton in brackish meromictic lake with deepwater chlorophyll maximum. Hydrobiologia 576:69-82
Zotina TA (2000) A study of structural-functional organization of Shira Lake phytoplankton. In: Proceedings of young investigator's conference (Krasnoyarsk Research Center-Siberian Branch of the Russian Academy of Sciences) ICM SB RAS Krasnoyarsk pp 20-22

Zotina TA, Tolomeyev AP, Degermendzhy NN (1999) Lake Shira, a Siberian salt lake: ecosystem structure and function. 1. Major physico-chemical and biological features. Int J Salt Lake Res 8:211-232 